\title{
Identification of rare DNA sequence variants in high-risk autism families and their prevalence in a large case/control population
}

Nori Matsunami ${ }^{1 \dagger}$, Charles H Hensel ${ }^{2^{*}}$, Lisa Baird ${ }^{1}$, Jeff Stevens ${ }^{1}$, Brith Otterud ${ }^{1}$, Tami Leppert ${ }^{1}$, Tena Varvil ${ }^{1}$, Dexter Hadley ${ }^{3}$, Joseph T Glessner ${ }^{3}$, Renata Pellegrino ${ }^{3}$, Cecilia Kim³ ${ }^{3}$, Kelly Thomas ${ }^{3}$, Fengxiang Wang ${ }^{3}$, Frederick G Otieno ${ }^{3}$, Karen $\mathrm{Ho}^{2}$, Gerald B Christensen ${ }^{4}$, Dongying $\mathrm{Li}^{5}$, Rytis Prekeris ${ }^{5}$, Christophe G Lambert ${ }^{4}$, Hakon Hakonarson ${ }^{3,6}$ and Mark F Leppert ${ }^{1}$

\begin{abstract}
Background: Genetics clearly plays a major role in the etiology of autism spectrum disorders (ASDs), but studies to date are only beginning to characterize the causal genetic variants responsible. Until recently, studies using multiple extended multi-generation families to identify ASD risk genes had not been undertaken.

Methods: We identified haplotypes shared among individuals with ASDs in large multiplex families, followed by targeted DNA capture and sequencing to identify potential causal variants. We also assayed the prevalence of the identified variants in a large ASD case/control population.

Results: We identified 584 non-conservative missense, nonsense, frameshift and splice site variants that might predispose to autism in our high-risk families. Eleven of these variants were observed to have odds ratios greater than 1.5 in a set of 1,541 unrelated children with autism and 5,785 controls. Three variants, in the RAB11FIP5, $A B P 1$, and JMJD7-PLA2G4B genes, each were observed in a single case and not in any controls. These variants also were not seen in public sequence databases, suggesting that they may be rare causal ASD variants. Twenty-eight additional rare variants were observed only in high-risk ASD families. Collectively, these 39 variants identify 36 genes as ASD risk genes. Segregation of sequence variants and of copy number variants previously detected in these families reveals a complex pattern, with only a RAB11FIP5 variant segregating to all affected individuals in one two-generation pedigree. Some affected individuals were found to have multiple potential risk alleles, including sequence variants and copy number variants (CNVs), suggesting that the high incidence of autism in these families could be best explained by variants at multiple loci.

Conclusions: Our study is the first to use haplotype sharing to identify familial ASD risk loci. In total, we identified 39 variants in 36 genes that may confer a genetic risk of developing autism. The observation of 11 of these variants in unrelated ASD cases further supports their role as ASD risk variants.
\end{abstract}

Keywords: Familial autism, Haplotype sharing, DNA sequence variants, Case/control study

\footnotetext{
* Correspondence: chensel@lineagen.com

${ }^{\dagger}$ Equal contributors

Lineagen, Inc, Salt Lake City, UT, USA

Full list of author information is available at the end of the article
} 


\section{Background}

Twin and family studies clearly demonstrate that genetics plays a major role in the etiology of ASDs [1-7]. However, family-based approaches using sib-ships or nuclear families have not resulted in the identification of genes or variants that explain a significant portion of the affected population. Similarly, genetic linkage studies have identified a number of chromosomal regions that are thought to contain genes that predispose to ASDs, but identification of the relevant gene(s) in these regions has proven difficult.

More recent analyses have revealed that many of the point mutations thought to predispose children to ASDs were not present in either parent, and thus occurred spontaneously in the affected individuals [8-12]. Such de novo variants likely account for as much as 20 to $30 \%$ of the genetic variation which results in ASDs. Additional cases are likely due to recessive inheritance of nonfunctional or hypo-functional alleles, but autosomal recessive inheritance is thought to explain only about $1 \%$ of autism cases [13,14].

In addition to single nucleotide variants and small insertions/deletions that can be identified by DNA sequencing, larger deletions or duplications (copy number variants, CNVs) have been shown to play a role in the etiology of ASDs [15-27]. Despite the observed inheritance of many ASD predisposition CNVs from an unaffected parent, the lack of extended, multi-generation pedigrees has precluded a comprehensive analysis of segregation of putative ASD predisposition CNVs and single nucleotide polymorphisms (SNPs) and the characterization of other genetic factors necessary for their expression.

The large families available in Utah coupled with the willingness of family members to participate in genetic studies have resulted in the identification of a large number of disease predisposition genes for both Mendelian and complex diseases. The pedigrees used in this study were part of a 70-family linkage study published previously [28] and two smaller studies that evaluated a single extended pedigree in this collection of families $[29,30]$. In this work, we analyzed members of 26 extended multi-generational ASD families and four twogeneration multiplex ASD families by performing haplotype sharing analysis to identify chromosomal regions that might harbor ASD predisposition genes. We then used DNA capture and sequencing of all genes in shared regions and of additional candidate autism risk genes to identify SNPs that might predispose to ASD in these families. These SNPs were analyzed in a large case/control study and for segregation in these families. We also evaluated the segregation of CNVs, reported previously [27], in these families. Consistent with earlier studies, no single locus could account for more than a subset of the affected individuals in any extended pedigree. In particular, multiple potential risk alleles, including in some cases CNVs and SNPs, were identified in an extended pedigree, suggesting that no single variant is the genetic predisposition locus for all affected family members. The data presented here identify several genes that may harbor ASD predisposition mutations, and add to the growing list of genes that are targets for clinical DNA sequencing to aid in the understanding of an ASD genetic diagnosis. These data further suggest that in some individuals multiple genetic variants may be necessary to elicit the observed clinical characteristics and that for a complete understanding of ASD genetics, both sequence variants and CNVs must be analyzed.

\section{Methods \\ DNA samples}

A total of 386 DNA samples from 26 extended multigeneration and four two-generation Utah multiplex ASD pedigrees were used in this study. Families were ascertained and recruited using the Utah Population Database (UPDB) as described [28]. Affection status was determined using the Autism Diagnostic Interview-Revised (ADI-R) and the Autism Diagnostic Observation Schedule (ADOS), for both the familial ASD cases and the unrelated ASD cases, as described previously [27]. The average number of affected individuals in each pedigree is 7.9. The pedigrees described here are a subset of those described previously [28]. Pedigree details are shown in Additional file 1: Table S1. The 55 samples used for our previous $\mathrm{CNV}$ discovery were included in these families. A total of 9,000 DNA samples previously described in a case/control study [27], including 3,000 individuals with ASD and 6,000 controls, were used to evaluate these variants in a broader population. All samples collected for the work described here were collected under methods approved by the University of Utah Institutional Review Board (IRB) (University of Utah IRB\#: 6042-96) or The Children's Hospital of Philadelphia IRB (CHOP IRB\#: IRB 06-004886). Patients and their families were recruited through the University of Utah Department of Psychiatry or The Children's Hospital of Philadelphia clinic or CHOP outreach clinics. Written informed consent was obtained from the participants or their parents using IRB approved consent forms prior to enrollment in the project. There was no discrimination against individuals or families who chose not to participate in the study. All data were analyzed anonymously and all clinical investigations were conducted according to the principles expressed in the Declaration of Helsinki.

\section{SNP microarray genotyping}

Affymetrix $250 \mathrm{~K}$ NspI SNP chip genotyping was carried out on all 386 DNA samples using the manufacturer's recommended procedure. Genotypes were called by Affymetrix Genotyping Console software using the BRLMM 
[31] genotype calling algorithm. Only SNPs with call rates greater than or equal to $99 \%$ were used for further analyses. SNPs demonstrating Mendelian errors also were identified using PedCheck [32] and were excluded.

\section{Shared haplotype analysis}

We performed shared haplotype analysis on each pedigree to identify genomic regions that have significant sharing among the affected individuals in that pedigree. The HapShare algorithm [33] was used to perform haplotype phasing based on Mendelian inheritance and to identify shared genomic segments. The comparisons included $\mathrm{N}$ out of $\mathrm{N}$ affected individuals, (N-1) out of $\mathrm{N}$, $(\mathrm{N}-2)$ out of $\mathrm{N},(\mathrm{N}-3)$ out of $\mathrm{N}$, and so on (See Figure one in reference [33]). In two-generation pedigrees, in some cases co-segregation of haplotypes was observed in all affected individuals analyzed, but the shared regions were large, including up to half of a chromosome. Consequently, shared regions from nuclear families were not selected for sequencing unless they overlapped regions observed in additional families.

\section{Custom targeted exome DNA sequencing}

NimbleGen (Roche NimbleGen, Inc., Madison, WI, USA) custom sequence capture arrays were designed to capture 2,000 base pairs upstream of the transcription start site and all exons and exon-intron boundaries of genes within the shared genomic segments. An additional 23 genes from outside of our haplotype sharing regions were selected from the literature based on their potential roles in autism or neuronal functions (see Additional file 1: Table S2). A total of approximately 1,800 genes were captured. Capture and Illumina DNA sequencing were performed by the Vanderbilt University Microarray Shared Resource facility on DNA from 26 affected individuals from 11 families that showed sharing of genomic segments. Short reads were aligned to the National Center for Biotechnology Information (NCBI) reference human genome build 36 (GRCh36/ hg18) and variants were called using the software alignment and variant calling methods described in Table 1 [34-36]. Potential variants detected by at least two of the methods were selected for further analysis.

Table 1 Sequence alignment and variant detection methods

\begin{tabular}{ccc}
\hline & $\begin{array}{c}\text { Alignment and } \\
\text { assembly }\end{array}$ & $\begin{array}{c}\text { Sequence variant } \\
\text { detection }\end{array}$ \\
\hline Method 1 & Bowtie & Maq \\
Method 2 & MOSAIK & GigaBayes \\
Method 3 & $\begin{array}{c}\text { CLC Bio Genomics } \\
\text { Workbench (CLC Bio Inc.) }\end{array}$ & CLC Bio Genomics Workbench \\
\hline
\end{tabular}

(CLC Bio Inc., Cambridge, MA, USA).

\section{Variant annotation}

In silico functional analysis was carried out initially using cSNP classifier, a preliminary program later incorporated into VAAST [37], to classify variants as synonymous, conservative missense, non-conservative missense, nonsense, frameshift, or splice site changes. Later, variants were reannotated using the ANNOVAR program [38]. The KnownGene and RefSeq gene tracks from the UCSC genome browser were used to annotate functional variants, and the LiftOver tool was used to convert human genome build 36 (GRCh36/hg18) coordinates to human genome build 37 (GRCh37/hg19) coordinates [39,40].

\section{Custom microarray design and array processing}

Design of the custom iSelect Infinium ${ }^{\text {TM }}$ II BeadChip array (Illumina Inc., San Diego, CA, USA) including probes for 2,799 putative functional candidate SNPs and 7,134 CNV probes was described previously [27]. The custom iSelect array was processed on 3,000 case and 6,000 control samples at the Center for Applied Genomics at The Children's Hospital of Philadelphia (CHOP) [27]. The same array was also used to analyze DNA from 196 Utah discovery cohort family members at the University of Utah Genomics Core facility for variant validation and analysis of SNP segregation in families.

\section{Array data quality control Sample QC}

Subjects were withheld from SNP analysis if any of the following were true: 1) subsequent to genotyping, the DNA sample was of apparent poor quality, evidenced by very low call rates $(\mathrm{N}=134) ; 2)$ the subject was identified as a trisomy-21 ( $\mathrm{N}=51)$; 3$)$ the subject was outside of the central cluster of Caucasian subjects identified by principal component analysis (PCA) $(\mathrm{N}=903)$ [27].

Relatedness estimation further indicated that some of the case subjects and controls were part of families with multiple relatives represented in the data. Re-evaluation of family structure in the sample cohorts used subsequently identified additional relationships. Subsequent association tests were therefore conducted using only one member of each known family in order to reduce the possibility of statistical confounding due to relatedness. For these tests, the subject selected from each family was the individual located nearest to the median centroid of the first two principal components. The number of subjects removed due to relatedness was 688 . This resulted in a final sample set for association testing comprising 7,326 subjects, of which 1,541 were cases and 5,785 were controls.

PCA was used to avoid artifacts due to population stratification. Principal components were calculated in Golden Helix SNP and Variation Suite (SVS) using default settings. All subjects were included in the 
calculation except those that failed sample quality control (QC). Prior to calculating principal components, the SNPs were filtered according to the following criteria: autosomes only, call rate $>0.95$, minor allele frequency (MAF) $>0.05$, linkage disequilibrium $\mathrm{R}^{2}<25 \%$ for all pairs of SNPs within a moving window of 50 SNPs. Two thousand and eight SNPs, including those used for CNV analysis, were used for the principal component calculations. No genotype data were available for reference populations, as would typically be preferred for making inferences about population stratification. However, a self-reported ethnicity variable was available for most subjects. A plot of the first two principal components shows a primary central cluster of subjects, with outlier groups extending along two axes. These roughly correspond to Asian and African-American ancestry as selfreported in the phenotype data. A simple outlier detection algorithm was applied to stratify the subjects into two groups representing the most probable Caucasians and non-Caucasians. This was done by first calculating the Cartesian distance of each subject from the median centroid of the first two principal component vectors. After determining the third quartile (Q3) and inter-quartile range (IQR) of the distances, any subject with a distance exceeding:

$$
\mathrm{Q} 3+1.5 \times \mathrm{IQR}
$$

was determined to be outside of the main cluster, and therefore non-Caucasian. Six hundred and eighty-two subjects were placed in the non-Caucasian category. A graphical representation of the results of this PCA analysis were reported previously [27].

\section{SNP QC}

Prior to association testing, SNPs were evaluated for call rate, Hardy-Weinberg equilibrium (HWE) and allele frequency. All SNPs with call rates lower than 99\% were removed from further analysis. No SNPs had significant Hardy-Weinberg disequilibrium.

\section{Laboratory confirmation of SNPs and CNVs}

For molecular validation of SNPs, PCR products were first screened by LightScanner High Resolution Melt curve analysis (BioFire Diagnostics Inc., Salt Lake City, UT, USA) for the presence of sequence variants. PCR primer sequences are shown in Additional file 1: Table S3. Any samples that gave abnormal melt profiles were sequenced using the Sanger method at the University Utah Sequencing Core facility to confirm the presence of a sequence variant. For CNVs, pre- or customdesigned TaqMan copy number assays (Applied Biosystems Inc., Foster City, CA, USA) were used as described previously [27].

\section{Protein binding assays}

All glutathione S-transferase (GST)-tagged proteins were expressed and purified as described previously [41]. To test Rab11FIP5 binding to various Rab GTPases, purified recombinant FIP5(490-653) or FIP5(490-653)-P652L were incubated with glutathione beads coated with GST, GST-Rab11a, GST-Rab4a or GST-Rab3a in the presence of $1 \mu \mathrm{m}$ GMP-PNP. Beads were then washed with PBS and eluted with $1 \%$ sodium dodecyl sulphate (SDS). Eluates were then analyzed for the presence of FIP5 (490-653) by immunoblotting with anti-Rab11FIP5 antibodies. A similar assay also was used to test the ability of Rab11FIP5 (wild-type or P652L mutant) to dimerize.

\section{Flow cytometry analysis of transferrin recycling}

To test the effect of the Rab11FIP5-P652L mutant on endocytic recycling, the transferrin recycling assay was used as described previously [42]. Briefly, HeLa cells expressing either wild-type FIP5-GFP or FIP5-GFP-P652L were incubated with transferrin conjugated to Alexa488. Cells were then washed and incubated with serumsupplemented media for varying amounts of time. The cell-associated (not recycled) Tf-Alexa488 was analyzed by flow cytometry.

\section{Results}

To identify genes that predispose to ASDs in multiplex ASD families, we took a haplotype sharing/custom DNA capture and sequencing approach. We utilized the workflow outlined in Figure 1, first to identify chromosomal regions with excessive sharing among affected individuals in multiplex ASD families. We then used sequence capture to identify potential functional sequence variants in the genes lying in the shared regions, as well as in additional ASD candidate genes. Finally, we evaluated the segregation of those variants in our ASD families and determined their prevalence in a large set of ASD cases and a large set of controls. The details of this process are described below.

\section{Affymetrix $250 \mathrm{~K}$ SNP genotyping and haplotype sharing} SNP genotyping was carried out on 386 DNA samples from 26 extended multi-generation and four twogeneration Utah multiplex ASD pedigrees. SNPs with no map location were not included in the analysis. The average call rate was $99.1 \%$ for the entire dataset.

We used the HapShare method [33] to identify genomic regions that have significant sharing among the affected individuals in each of the 30 pedigrees we studied. Paternal and maternal haplotypes were determined based on Mendelian inheritance using only informative markers. These haplotypes then were compared among affected individuals within each extended or nuclear family. We selected 18 regions of haplotype sharing 


\section{Discovery of candidate functional sequence variants}

250K SNP microarray genotyping

386 family members from 26 extended and four 2 generation ASD families

Haplotype-sharing analysis

25 chromosomal regions identified

Custom sequence capture and Next-Gen DNA sequencing

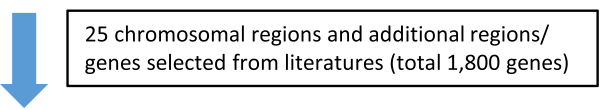

DNA Sequence alignment and variant detection In Silico functional variant annotation

2,825 putative candidate functional sequence variants

Design custom microarray

Successful probe design for 2,799

variants=candidate variants

Custom microarray manufacturing

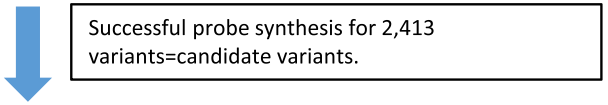

Array processing and analysis, case/control and discovery family samples

Discard samples due to: -Poor DNA sample quality

-Whole-chromosome abnormalities

-Sample from duplicate enrollment

-Samples from close relatives

\section{Sample QC, 3000 cases,} 6000 controls

\section{Principal component analysis}

-Recalculate and correct for principal components -Remove non-Caucasian samples to avoid errors due to population stratification

Select single sample from multiplex families based on PCA

631 cases removed from multiplex families, 39 related controls removed

Final set of unrelated Caucasian samples: 1541 cases, 5785 controls.

\section{Association testing/Segregation Analysis}

\section{SNPs with OR>1.5 (Table 3), 28 SNPs seen only in discovery families (Table 4)}

Figure 1 Workflow for sequence variant discovery and analysis. Only ethnicity and gender matched, unrelated, cases and controls were used for association testing. 
based on sharing in extended pedigrees for further analysis. The degree of sharing that we observed among affected individuals and the coordinates of the regions selected for DNA capture and sequencing are shown in Table 2. Two additional regions were selected for DNA capture and sequencing based on a published linkage analysis using an overlapping set of families [28].

\section{Sequence capture, sequence analysis and variant identification}

We performed capture and DNA sequencing using DNA from 26 affected individuals from 11 families that showed the best sharing of genomic segments. These samples included individuals from two-generation pedigrees that had shared haplotypes overlapping regions identified in the extended pedigrees. Eight to nine million 36 base short reads were obtained from each sample. The short reads alignment against the NCBI reference human genome build 36 revealed coverage of 86 to $97 \%$ of the designed capture area, with the average read depth over the designed capture area of 30 to $47 \mathrm{X}$. Because 1) the capture library was constructed in a directional manner, 2) all capture probes represented the same DNA strand, and 3) the library was sequenced only from one direction, some portions of exons lacked the sequence depth of coverage that we desired. Consequently, there could be additional variants (false negative results) that we did not detect in some of the genes. For example no variants were identified on haplotypes that segregate to all affected individuals in pedigree 10 on chromosomes 2 and 14 (Additional file 2: Figure S1, A and B, Additional file 3: Figure S2). Nonetheless, variant calling using the three methods shown in Table 1 identified over one million sequence variants called by at least two of the three methods. Analysis using cSNP classifier resulted in the detection of 2,825 putative functional candidate SNPs, including 210 nonsense variants, 1,614 nonconservative missense variants, 35 frameshift variants and 966 splice site variants.

We chose to design a custom microarray to evaluate the variants that we identified by sequencing in order to 1) interrogate the entire set of candidate functional SNPs in the discovery families for validation, and 2) to perform a large scale case/control study to determine if any of the variants identified predisposition genes important to the broad population of children with ASD (Figure 1). Following array design and manufacture, probes for 2,413 variants were created successfully. Custom microarray experiments on Utah discovery and CHOP case/control samples revealed 584 out of 2,413 putative variants to be polymorphic. The complete list of polymorphic variants is shown in Additional file 1: Table S4. The remaining array probes did not detect a non-reference sequence allele. These 1,829 variants thus were interpreted to be false positives due to the variant calling and alignment process of single end sequence data.

Table 2 Chromosomal regions selected for sequencing based on haplotype sharing

\begin{tabular}{|c|c|c|c|c|}
\hline Eighteen shared haplotype regions & Chromosome & Location (hg18) & Location (hg19) & Affecteds sharing haplotype \\
\hline 2p14-p12 & 2 & $65612029-76349401$ & $65758525-76495893$ & 6 of 6 \\
\hline $2 q 23-q 31$ & 2 & $153638312-174296304$ & $153930066-174588058$ & 6 of 6 \\
\hline $2 q 37$ & 2 & $231435643-238617145$ & 231727399-238952406 & 5 of 7 \\
\hline $3 q 13$ & 3 & $111604019-112685490$ & $110121329-111202800$ & 4 of 7 \\
\hline $3 q 26-q 27$ & 3 & $174594938-185701563$ & $173112244-184218869$ & 4 of 7,4 of 4 \\
\hline $4 q 28-q 31$ & 4 & $137362554-141629142$ & $137143104-141409692$ & 6 of 6 \\
\hline $7 p 21$ & 7 & $7381742-11861952$ & 7415217-11895427 & 4 of 4,4 of 6 \\
\hline $7 p 14$ & 7 & $36090817-41521542$ & $36124292-41555017$ & 4 of 7 \\
\hline $7 q 21-q 31$ & 7 & $90511244-107823133$ & $90673308-108035897$ & 5 of $8^{a}$ \\
\hline $7 q 35-36$ & 7 & $142750349-151152511$ & $143040227-151521578$ & 4 of 6 \\
\hline $12 q 21$ & 12 & $76119990-77788028$ & $77595859-79263897$ & 5 of 7 \\
\hline $12 q 21$ & 12 & $79689788-87939487$ & $81165657-89415356$ & 5 of 8 \\
\hline $14 q 11-q 21$ & 14 & $22912579-45661808$ & $23842739-46592058$ & 3 of 4,6 of 6 \\
\hline $14 q 32$ & 14 & $92331535-103509782$ & $93261782-104440029$ & 4 of 4 \\
\hline $15 q 12-q 21$ & 15 & $24339787-43759484$ & $26788694-45972192$ & 3 of 4,4 of 6,5 of 8 \\
\hline $16 q 22-23$ & 16 & $73415053-77780513$ & $74857552-79223012$ & 4 of 7,5 of 6,3 of 4 \\
\hline 20p11-q13 & 20 & $25253250-41225971$ & $25305250-41792557$ & 4 of 7 \\
\hline $20 q 13$ & 20 & $49062886-57757418$ & $49629479-58324023$ & 5 of 6,5 of 6 \\
\hline
\end{tabular}

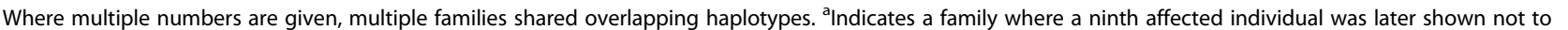
share the same haplotype. 
All autosomal SNP variants were tested for association with autism in our case/control study using an allelic association test. Statistical significance of each was assessed using both Fisher's exact test and a chi-squared test. The allelic association test detects any significant result regardless of the direction of the effect. Eleven SNPs (see clustering in Additional file 4: Figure S3) were either unique to cases or had odds ratios (minor allele) greater than 1.5 (Table 3). We prioritized the variants observed in our case/control study for additional work based on an odds ratio cutoff of 1.5. We also included variants unique to cases. We chose this approach rather than using $P$ values since these variants were too rare to select based on $P$ values, and for relatively rare diseases odds ratios are approximately equivalent to relative risk values. In addition, 28 SNPs were detected only in the Utah discovery cohort and not in the CHOP cases or controls (Table 4). We consider these 28 SNPs to be potential ASD risk alleles because a) they are rare or non-existent in the general population and thus could represent 'private mutations', b) they may affect protein function, and c) they segregate to one or more children with autism in high-risk autism pedigrees. Thus, we characterize these 39 SNPs, found in 36 different genes, as potential autism risk variants. Each of these 39 variants was localized to our targeted regions (Table 2), and 30 of the 39 variants were predicted to be damaging by at least one program embedded in ANNOVAR [38], including SIFT, Polyphen2, LRT and MutationTaster. Details of the analysis of these variants are shown in Additional file 1: Table S5. All 39 SNPs were further confirmed by Sanger DNA sequencing of PCR amplicons (see Additional file 5: Figure S4, Additional file 6: Figure S5, for sequence chromatograms). The transcripts used for variant annotation are found in Additional file 1: Table S5.

\section{Segregation of variants in high-risk pedigrees}

To determine the potential significance of variants that we identified, we evaluated the segregation pattern of these variants in the relevant pedigrees. We identified potentially detrimental sequence variants in 10 of the 11 pedigrees from which individuals were selected for DNA capture and sequencing. Several of the pedigrees segregated more than one variant, indicating the complexity of the underlying genetics in high-risk ASD pedigrees. Moreover, many of these pedigrees also have CNVs that were identified in our previous work [27]. Adding to the genetic complexity, many of these CNVs also segregate to affected individuals. Five families that demonstrate these complex inheritance patterns are shown here (Figures 2, 3, 4, 5 and 6). Five additional pedigrees with multiple variants are shown in Additional file 7: Figure S6, Additional file 8: Figure S7, Additional file 9: Figure S8, Additional file 10: Figure S9, Additional file 3: Figure S9.

Pedigree 1 (Figure 2) shows a two-generation family cosegregating a missense variant in RAB11FIP5 (Table 4). This variant is present in the mother and segregates to all three male affected children in the family, and not to the unaffected female child. RAB11FIP5 has previously been implicated as an ASD risk gene based on its disruption by a translocation observed in a 10 year-old male child with a diagnosis of pervasive developmental disorder not otherwise specified (PDD-NOS) [43]. The variant detected in pedigree 1 results in a P652L substitution. Proline is conserved at this residue in all of the mammalian RAB11FIP5 genes sequenced to date, suggesting that it is important

Table 3 Sequence variants identified in families and observed in the case/control study

\begin{tabular}{|c|c|c|c|c|c|c|c|c|c|c|c|c|}
\hline $\begin{array}{l}\text { Variant } \\
\text { (Ref/Obs) }\end{array}$ & Gene & $\begin{array}{l}\text { Coordinate } \\
\text { (hg19) }\end{array}$ & $\begin{array}{l}\text { Fisher's } \\
\text { exact P }\end{array}$ & Chi-squared P & $\begin{array}{l}\text { Odds ratio } \\
\text { (Minor } \\
\text { allele) }\end{array}$ & $\begin{array}{l}\text { Odds ratio } \\
95 \% \text { lower } \\
\text { confidence } \\
\text { bound }\end{array}$ & $\begin{array}{l}\text { Odds ratio } \\
95 \% \text { upper } \\
\text { confidence } \\
\text { bound }\end{array}$ & $\begin{array}{l}\text { Het. } \\
\text { cases }\end{array}$ & $\begin{array}{c}\text { Het. } \\
\text { controls }\end{array}$ & $\begin{array}{l}\text { W-T } \\
\text { cases }\end{array}$ & $\begin{array}{c}\text { W-T } \\
\text { controls }\end{array}$ & Variant \\
\hline $\mathrm{G} / \mathrm{T}$ & RAB11FIP5 & chr2:73302656 & $2.10 \mathrm{E}-01$ & $5.27 \mathrm{E}-02$ & infinite & $\mathrm{N} / \mathrm{A}$ & $\mathrm{N} / \mathrm{A}$ & 1 & 0 & 1,540 & 5,785 & $\mathrm{P} 652 \mathrm{H}$ \\
\hline $\mathrm{G} / \mathrm{C}$ & ABP1 & chr7:150554592 & $2.10 \mathrm{E}-01$ & $5.27 \mathrm{E}-02$ & infinite & N/A & N/A & 1 & 0 & 1,540 & 5,785 & R345P \\
\hline T/A & $\begin{array}{l}\text { JMJD7- } \\
\text { PLA2G4B }\end{array}$ & chr15:42133295 & 2.10E-01 & 5.27E-02 & infinite & N/A & N/A & 1 & 0 & 1,540 & 5,785 & splice site \\
\hline $\mathrm{C} / \mathrm{T}$ & C7orf10 & chr7:40498796 & 4.02E-02 & $3.13 \mathrm{E}-02$ & 1.62 & 1.04 & 2.53 & 28 & 65 & 1,513 & 5,720 & $\begin{array}{l}\text { R288W, } \\
\text { splice site }\end{array}$ \\
\hline $\mathrm{C} / \mathrm{T}$ & AKAP9 & chr7:91724455 & $6.62 \mathrm{E}-02$ & 4.44E-02 & 3.76 & 0.94 & 15.03 & 4 & 4 & 1,537 & 5,781 & R3233C \\
\hline$C / T$ & HEPACAM2 & chr7:92825188 & $5.84 \mathrm{E}-02$ & $3.88 \mathrm{E}-02$ & 1.83 & 1.02 & 3.27 & 17 & 35 & 1,524 & 5,750 & G398R \\
\hline $\mathrm{G} / \mathrm{T}$ & ALX1 & chr12:85674230 & 2.22E-02 & 1.49E-02 & 1.75 & 1.11 & 2.77 & 27 & 58 & 1,514 & 5,727 & R64L \\
\hline $\mathrm{G} / \mathrm{A}$ & AP1G2 & chr14:24035159 & $1.66 \mathrm{E}-01$ & 1.35E-01 & 1.67 & 0.85 & 3.30 & 12 & 27 & 1,529 & 5,757 & R99C \\
\hline $\mathrm{G} / \mathrm{C}$ & CLMN & chr14:95679692 & $2.29 \mathrm{E}-01$ & $2.23 \mathrm{E}-01$ & 1.67 & 0.73 & 3.84 & 8 & 18 & 1,533 & 5,767 & P158A \\
\hline $\mathrm{G} / \mathrm{A}$ & MOK & chr14:102749873 & $1.97 \mathrm{E}-01$ & $1.55 \mathrm{E}-01$ & 3.76 & 0.53 & 26.67 & 2 & 2 & 1,539 & 5,783 & Q22X \\
\hline$G / A$ & OIP5 & chr15:41611874 & 3.77E-01 & $2.53 \mathrm{E}-01$ & 2.25 & 0.54 & 9.44 & 3 & 5 & 1,538 & 5,780 & S165F \\
\hline
\end{tabular}


Table 4 Sequence variants observed only in high-risk ASD families

\begin{tabular}{|c|c|c|c|c|c|c|c|}
\hline $\begin{array}{l}\text { Variant } \\
\text { (Ref/Obs) }\end{array}$ & Gene & Coordinate (hg19) & $\begin{array}{l}\text { Pedigree } \\
\text { structure }\end{array}$ & $\begin{array}{l}\text { Tested affecteds } \\
\text { in pedigree }\end{array}$ & $\begin{array}{l}\text { Affecteds } \\
\text { with variant }\end{array}$ & $\begin{array}{l}\text { Coding } \\
\text { change }\end{array}$ & ESP6500_ALL \\
\hline $\mathrm{G} / \mathrm{A}$ & RAB11FIP5 & chr2:73302656 & 2-Generation & 3 & 3 & P652L & \\
\hline$C / G$ & AUP1 & chr2:74756328 & Extended & 5 & 1 & R90S & \\
\hline T/C & SCN3A & chr2:165946964 & Extended & 6 & 1 & E1851G & \\
\hline T/C & ATP11B & chr3:182583394 & Extended & 9 & 2 & S451P & \\
\hline$A / G$ & KLHL6 & chr3:183226296 & 2-Generation & 5 & 4 & F154L, splicing & \\
\hline$C / T$ & AKAP9 & chr7:91736684 & Extended & 7 & 1 & R3832C & 0.000154 \\
\hline $\mathrm{G} / \mathrm{C}$ & PDK4 & chr7:95215047 & 2-Generation & 6 & 3 & S381X & \\
\hline$C / G$ & RELN & chr7:103214555 & Extended & 7 & 1 & $\mathrm{D} 1499 \mathrm{H}$ & 0.000231 \\
\hline $\mathrm{G} / \mathrm{A}$ & DCAF11 & chr14:24590630 & 2-Generation & 3 & 2 & G435R & \\
\hline $\mathrm{G} / \mathrm{A}$ & RNF31 & chr14:24617687 & Extended & 9 & 1 & splicing & \\
\hline $\mathrm{G} / \mathrm{C}$ & IRF9 & chr14:24634003 & Extended & 9 & 1 & $\mathrm{R} 277 \mathrm{~T}$ & \\
\hline $\mathrm{G} / \mathrm{A}$ & SDR39U1 & chr14:24909513 & 2-Generation & 6 & 2 & P220S & \\
\hline T/A & PRKD1 & chr14:30095731 & 2-Generation & 3 & 2 & D586V & \\
\hline$C / \mathrm{T}$ & SEC23A & chr14:39545251 & 2-Generation & 3 & 1 & G292D & \\
\hline $\mathrm{G} / \mathrm{A}$ & ITPK1 & chr14:93418316 & 2-Generation & 5 & 2 & P238L & \\
\hline $\mathrm{G} / \mathrm{A}$ & CCDC85C & chr14:99988547 & Extended & 9 & 1 & R300W & \\
\hline$A / G$ & C14orf2 & chr14:104381450 & 2-Generation & 6 & 5 & $126 \mathrm{~T}$ & \\
\hline $\mathrm{G} / \mathrm{T}$ & TRPM1 & chr15:31329966 & Extended & 5 & 1 & T857K & \\
\hline $\mathrm{T} / \mathrm{C}$ & FMN1 & chr15:33359761 & Extended & 9 & 3 & R109G & \\
\hline $\mathrm{G} / \mathrm{T}$ & PGBD4 & chr15:34395847 & Extended & 9 & 4 & G372V & 0.000231 \\
\hline$C / T$ & JMJD7 & chr15:42129054 & Extended & 9 & 4 & R260C & 0.00068 \\
\hline $\mathrm{C} / \mathrm{T}$ & CASC4 & chr15:44620915 & Extended & 5 & 1 & R139X & \\
\hline $\mathrm{G} / \mathrm{C}$ & SPATA5L1 & chr15:45695534 & 2-Generation & 5 & 3 & D303H & \\
\hline$C / G$ & PYGO1 & chr15:55839207 & Extended & 7 & 1 & G92R & \\
\hline$C / G$ & PRTG & chr15:55916638 & Extended & 9 & 2 & A999P & \\
\hline $\mathrm{G} / \mathrm{A}$ & NUDT7 & chr16:77756514 & Extended & 9 & 4 & R12K, splicing & \\
\hline $\mathrm{G} / \mathrm{A}$ & DEFB124 & chr20:30053379 & Extended & 7 & 4 & P49L & 0.000154 \\
\hline$A / G$ & EPB41L1 & chr20:34809850 & Extended & 9 & 1 & D733G & \\
\hline
\end{tabular}

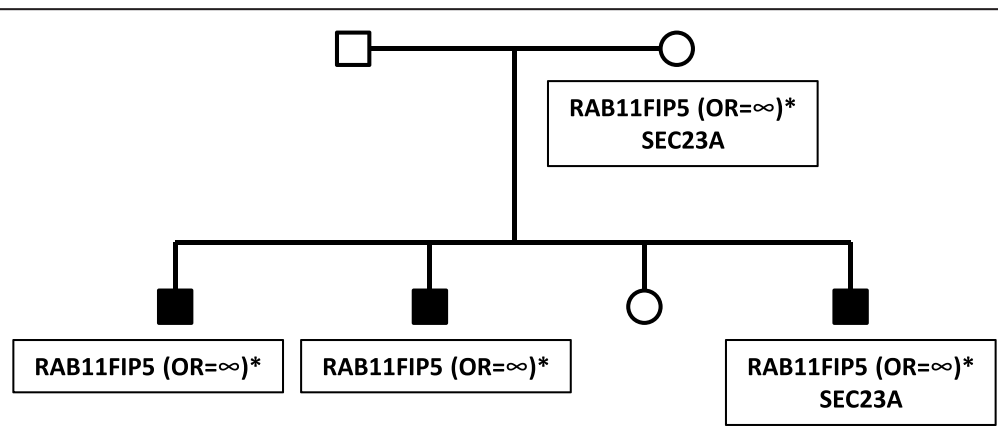

Figure 2 Co-segregation of a RAB11FIP5 variant. Two-generation pedigree (pedigree 1) with three male siblings affected with autism. Sequence variants identified in the family are shown in the black boxes. Open boxes - unaffected male family members; open circles - unaffected female family members; filled boxes - affected male family members. Odds ratios for the variants observed in the case/control study are shown. Variants with no odds ratio were observed only in high-risk families. All family members were tested for all variants. 


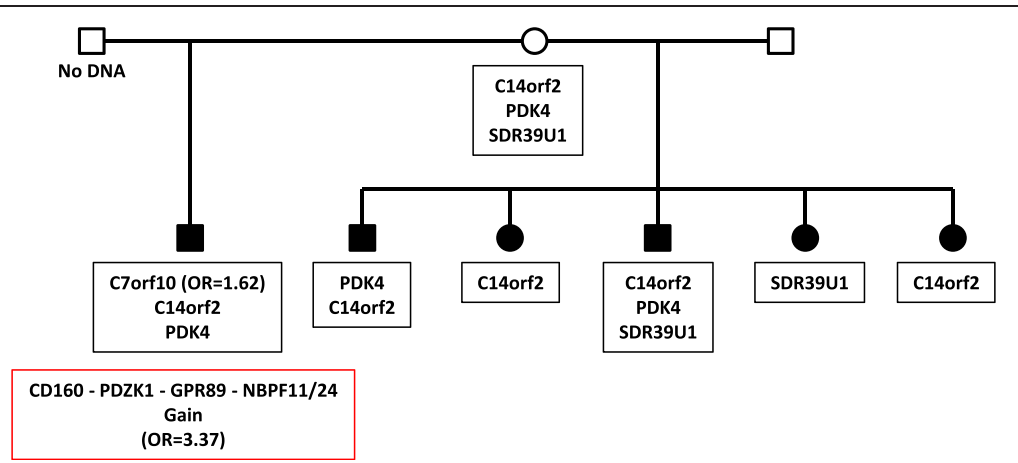

Figure 3 Segregation of C14orf2 variant. Two-generation pedigree (pedigree 2), with three affected female and two affected male siblings as well as an affected male half-sibling. The C140rf2 variant segregates to five of six affected children. Pedigree symbols are described in the legend for Figure 2. Sequence variants identified in the family are shown in the black boxes. A CNV found in the affected half-sibling [27] is shown in the red box. Odds ratios for variants observed in the case/control study are shown in parentheses. Variants with no odds ratio were observed only in high-risk families. All family members were tested for all variants unless no DNA was available. Individuals with no available DNA are indicated.

for protein function. A second individual, with a $\mathrm{P} 652 \mathrm{H}$ variant, was detected in our case/control study (Table 3) using our custom microarray. Neither the P652L substitution nor the $\mathrm{P} 652 \mathrm{H}$ substitution was observed in the ESP6500, 1,000 genomes project or dbSNP137 databases (Additional file 1: Table S5). Each of these variants was confirmed by Sanger sequencing (See Additional file 5: Figure S4, Additional file 6: Figure S5 for chromatograms). An additional affected individual of non-European descent, and thus not included in the case/control study, also carried the $\mathrm{P} 652 \mathrm{H}$ variant (data not shown). The presence of the $\mathrm{P} 652 \mathrm{H}$ variant in an additional individual with autism and not in any controls further supports the likelihood of variants in RAB11FIP5 contributing to autism risk.

Pedigree 2 (Figure 3) is a two-generation family with six affected individuals from two fathers. In this pedigree, five of the six affected individuals inherit a variant resulting in an $\mathrm{I} 26 \mathrm{~T}$ substitution in C14orf2. Two additional sequence variants, one each in the PDK4 and
SDR39U1 genes, segregate to three and two affected individuals respectively. In addition, a $\mathrm{CNV}$ gain $(\mathrm{OR}=3.37)$ described previously [27] is present in one affected individual. The C14orf2 and PDK4 variants were maternally inherited, while the C7orf10 and the CNV were either of paternal origin or occurred as de novo variants. Of the variants detected in this family, only the C7orf10 variant was observed in our case/control study. However, this variant had an odds ratio of 1.62 (95\% confidence interval 1.04 to $2.53)$, suggesting the possibility for a role in autism predisposition in the general population.

Pedigree 3 (Figure 4) also is a two-generation family, with five male children affected with autism. In this pedigree, four of the five affected individuals exhibit maternal inheritance of an F154L variant in the KLHL6 gene. This A/G nucleotide variant also is found at the first nucleotide of an exon and thus also may affect splicing of the KLHL6 primary transcript. In addition to this variant, three of the five offspring have a paternally inherited D303H missense variant in the SPATA5L1 gene while

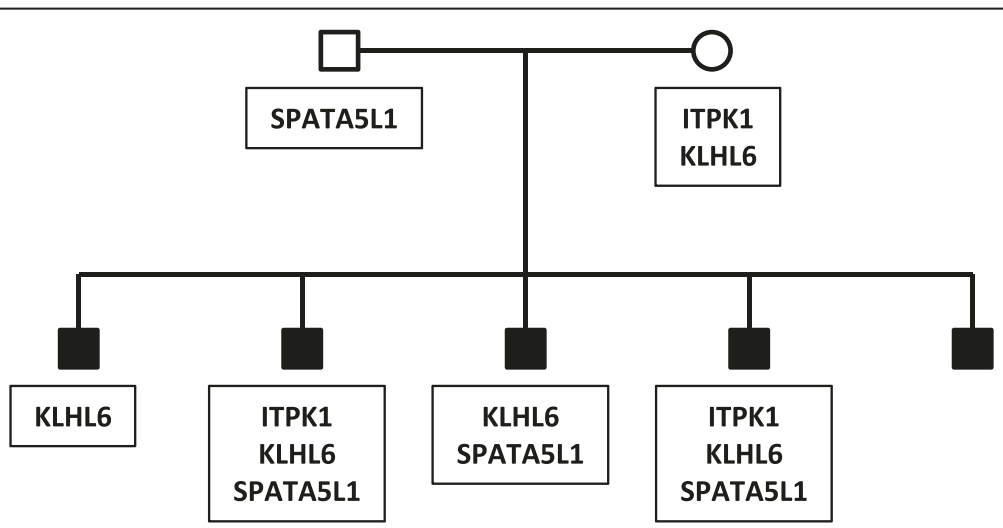

Figure 4 Segregation of KLHL6, SPATA5L1, and ITPK1 variants. Two-generation pedigree (pedigree 3), with five affected male siblings. Sequence variants identified in the family are shown in the black boxes. Pedigree symbols are described in the legend for Figure 2 . Variants with no odds ratio were observed only in high-risk families. All family members were tested for all variants. 


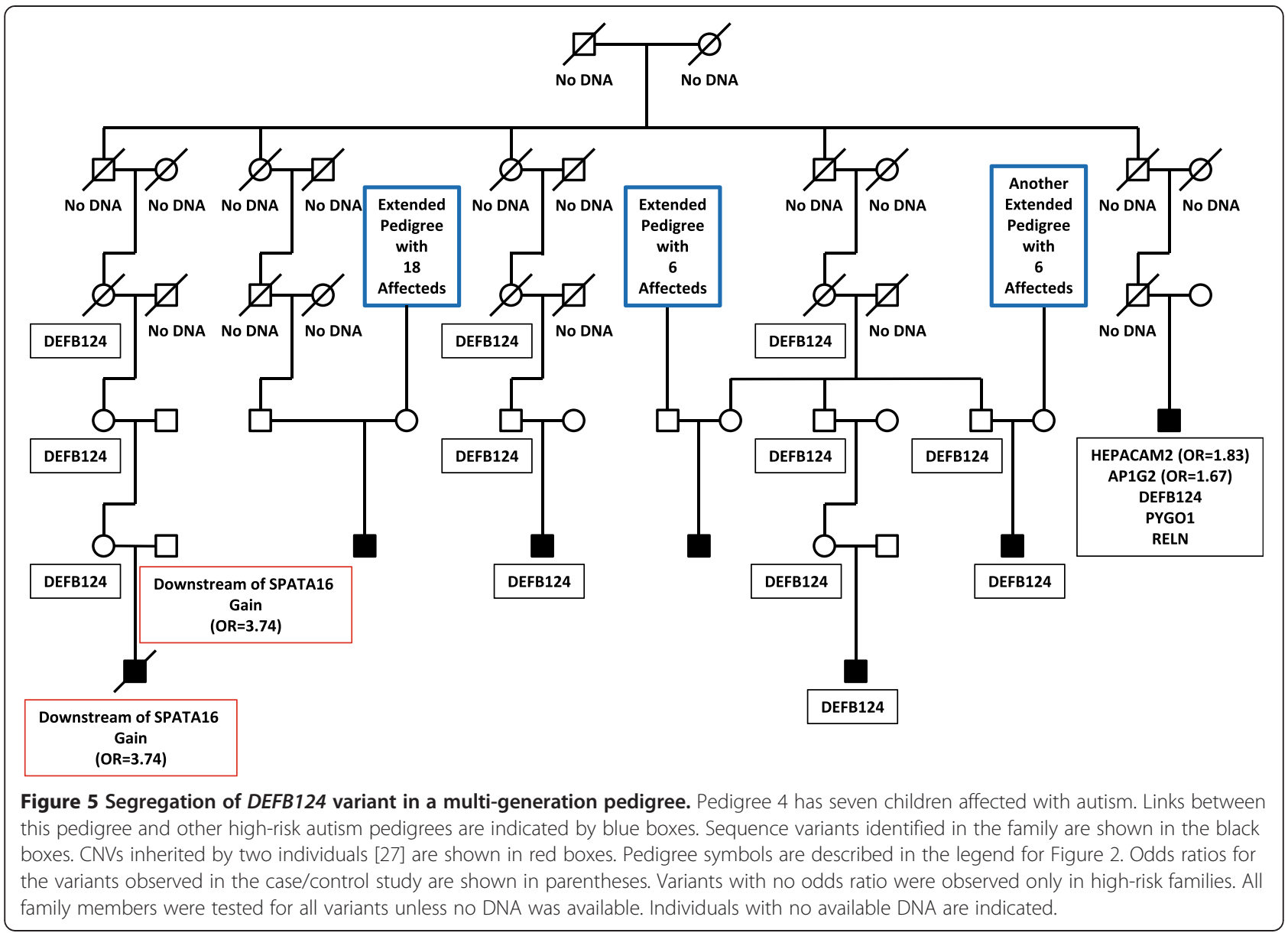

two of five also have a maternally inherited P238L change in the ITPK1 gene. One affected child does not inherit any of these variants. Of interest, none of the variants observed in this small family were observed in any cases or controls in our population study, demonstrating that they are not common autism predisposition loci.

Pedigree 4. (Figure 5) is a six generation family with an ancestor common to all seven male children that are affected with autism. These children all are in the fifth or sixth generations of the pedigree. Linkage analysis was performed previously on this family using Affymetrix $10 \mathrm{~K}$ SNP genotype data $[29,30]$, and three regions of significant linkage were identified. These include 3q13.2q13.31, 3q26.31-q27.3, and 20q11.21-q13.12. These three regions also were identified by haplotype sharing in this study (Figure 5, see Additional file 2: Figure S1C for chromosome 20 haplotype sharing). Four of the seven affected individuals in this family share a P49L variant that is the result of an $\mathrm{A} / \mathrm{G}$ transition in the DEFB124 gene on chromosome 20q11.21, consistent with the haplotype sharing that we observed (Additional file 2: Figure S1c) and with the published linkage result. This variant was not observed in cases or controls in our population study. One affected individual in this pedigree does not share the DEFB124 variant, but instead has a chromosome $3 \mathrm{q}$ gain $\mathrm{CNV}$, inherited from his father, that had an odds ratio of 3.74 in our previous study [27]. The elevated odds ratio suggests that this $\mathrm{CNV}$ is an autism risk locus.

Two additional affected individuals in pedigree 4 do not carry any variant that we detected in our families. However, as indicated in Figure 5, each of these two individuals is descended from a marry-in spouse with a strong family history of autism, suggesting the possibility of additional undetected variants.

Finally, one affected individual who carries the DEFB124 variant carries variants in the HEPACAM2 gene (odds ratio 1.83 in our population study, Table 3), the AP1G2 gene (odds ratio 1.67, Table 3), the PYGO1 gene and the RELN gene. Neither the RELN variant nor the PYGO1 variant was observed in the case/control study (Table 4). Interestingly, a recent unpublished clinical case identified a heterozygous deletion involving 15 exons of the RELN gene in a patient diagnosed with autism and behavior/conduct disorder (Rena Vanzo, personal communication). Homozygous or compound heterozygous mutations in RELN 


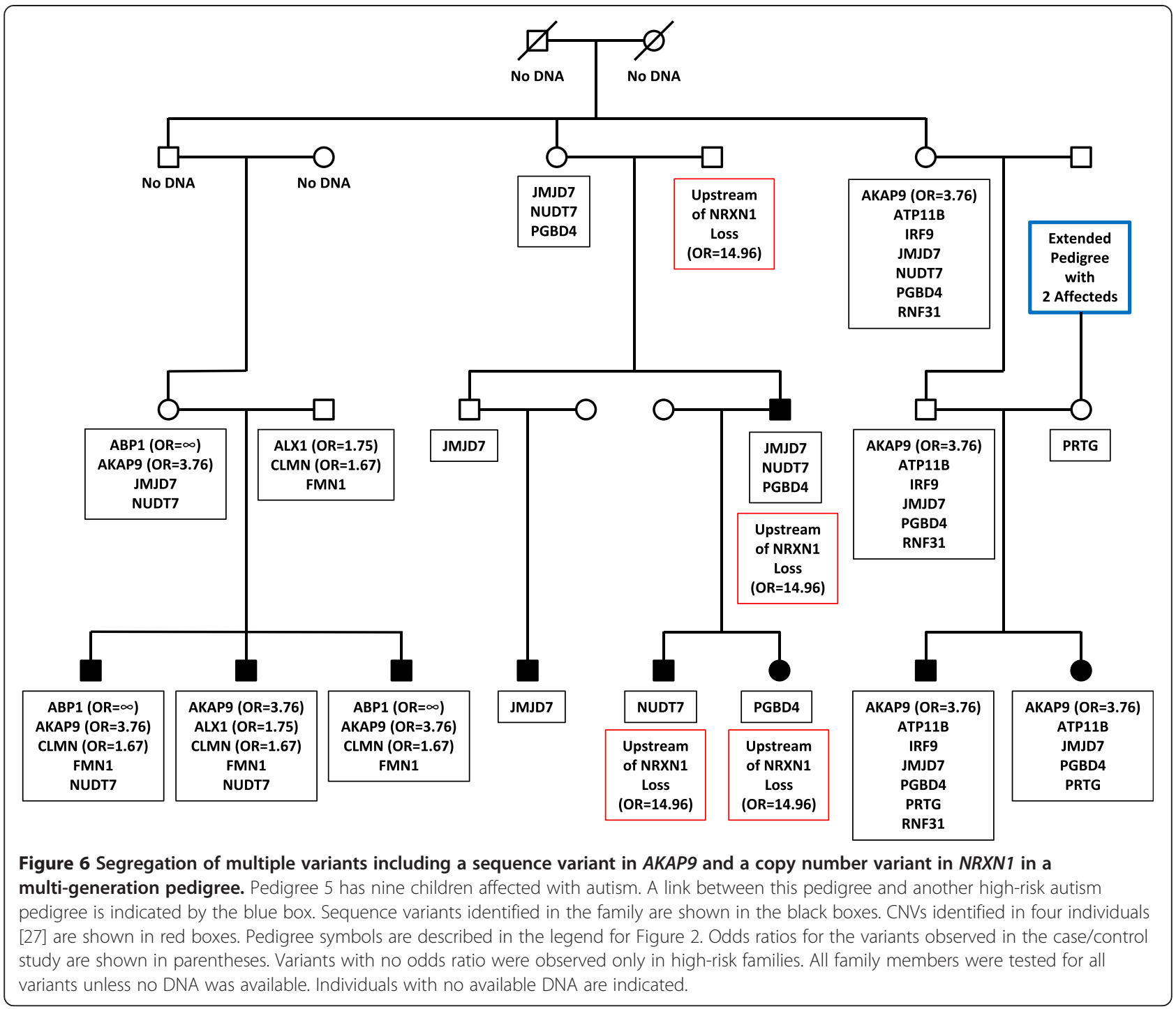

are associated with lissencephaly [44,45], but this RELN deletion is the first description of an individual with a developmental phenotype that may be due to haploinsufficiency at this locus.

Pedigree 5 (Figure 6) is a four-generation family with nine individuals affected with autism (seven male, two female). Two variants are of particular interest in this family. The first is a CNV including the $5^{\prime}$-flanking region of the NRXN1 gene. This CNV is inherited from a father who marries into the family in the second generation. This CNV segregates to three of the four descendants of this individual who are diagnosed with autism. An overlapping NRXN1 $\mathrm{CNV}$ was shown in our previous work to have an odds ratio of 14.96 [27], consistent with other publications suggesting a role for NRXN1 variants in autism, as well as other neurological disorders [46-48]. However, that $\mathrm{CNV}$ was shown to extend into the coding region of NRXN1, while TaqMan CNV analysis demonstrates that the CNV in pedigree 5 did not (data not shown). Thus, the significance of the NRXN1 CNV observed in this family is uncertain.

A second variant identified in this family, found on a haplotype shared by all five affected individuals in two branches of the family (Additional file 2: Figure S1c), is a $\mathrm{C} / \mathrm{T}$ transition in the AKAP9 gene that results in an R3233C missense substitution. Note that none of the individuals in these two branches of the family carry the NRXN1 CNV. The AKAP9 variant was observed in $4 / 1541$ cases and 4/5785 controls in our population study (odds ratio of 3.76, 95\% confidence interval 0.94 to 15.03 ) (Table 3). A second missense variant in the AKAP9 gene was observed in a single affected individual in a nuclear family (pedigree 6, Additional file 7: Figure S6). This second AKAP9 variant was not observed in the case/control study (Table 4). The AKAP family of proteins has been suggested to connect different biological pathways that are involved in nervous system development [49]. 
Pedigree 5 also segregates other variants that are inherited by multiple children affected with autism. One branch of the pedigree segregates a $\mathrm{G} / \mathrm{C}$ transversion in the CLMN gene that results in a P158A missense substitution. This variant yielded an odds ratio of 1.67 (95\% confidence interval 0.73 to 3.84 ) in our case/control study, suggesting that it is an ASD risk allele. A variant in the $A B P 1$ gene, also the result of a $\mathrm{G} / \mathrm{C}$ transversion and resulting in an $\mathrm{R} 345 \mathrm{P}$ missense substitution, was observed in two affected individuals in a single branch of the family. This variant was maternally inherited and not seen elsewhere in the pedigree. However, this variant was observed in 1/1,541 cases and 0/5,785 controls in our population study (Table 3 ) and was not observed in the ESP6500, 1,000 Genomes, or dbSNP137 databases (Additional file 1: Table S5), indicating that it may be a very rare ASD risk variant. Finally, a G/T transversion in the $A L X 1$ gene that results in an R64L missense substitution was paternally inherited by a single individual. This variant also was seen in pedigree 7 (Additional file 8: Figure S7) and was observed multiple times in our population study (27/1,541 cases and 58/5,785 controls) yielding an odds ratio of 1.75 (95\% confidence interval 1.11 to 2.77 ) (Table 3). Expression of this gene also may be increased by a downstream balanced translocation in a family with mental retardation, language delay and microcephaly that segregate with the translocation [50].

Pedigrees 8 to 10 are shown in Additional file 9: Figure S8, Additional file 10: Figure S9, Additional file 3: Figure S2. One of these pedigrees, pedigree 10, carried two haplotypes (chromosomes 2 and 14) segregating to all six affected individuals (Additional file 2: Figure S1a-b). Sequencing of the genes encompassed by these regions did not identify potential causal variants. This could be due to poor sequence coverage of some portions of the genes. However, sequencing of affected individuals in these families did result in the identification of variants that could be autism risk alleles. One of these variants, a G/A transition that result in a Q22X change in the $M O K$ gene observed in a single affected individual and inherited from her father, is interesting, as it was observed in our population study and yielded an odds ratio of 3.76 (95\% confidence interval 0.53 to 26.67) (Table 3). Other variants in pedigrees 8 to 10 (Additional file 9: Figure S8, Additional file 10: Figure S9, Additional file 3: Figure S2), including some only seen in Utah families and others seen in both families and in our population study also were identified. These variants are included in Table 3 and Table 4.

\section{Functional analysis of RAB11FIP5}

To uncover the functional consequences of the Rab11FIP5P652L variant we evaluated binding of Rab11FIP5 to Rab11. Rab11 is a small monomeric GTPase that mediates
Rab11FIP5 recruitment to endocytic membranes and is required for Rab11FIP5 function [41]. As shown in Additional file 11: Figure S10A, the P652L substitution did not affect Rab11FIP5 binding to Rab11, nor did it affect its specificity toward the Rab11 GTPase. It was previously shown that Rab11FIP5 forms homodimers and that its ability to dimerize is also required for Rab11FIP5 cellular functions [41]. Thus, we tested the effect of P652L substitution on Rab11FIP5 ability to dimerize. As shown in Additional file 11: Figure S10B, the Rab11FIP5P652L mutant was still able to form dimers. Consistent with in vitro binding data, FIP5-GFP-P652L endocytic localization in HeLa cells was also not affected (Additional file 11: Figure S10B-E).

It is now well established that Rab11FIP5 functions by regulating endocytic recycling [51]. To that end, we next tested whether Rab11FIP5-P652L has an effect on recycling of transferrin receptors in HeLa cells and found that the P652L substitution did not alter recycling (Additional file 11: Figure $\mathrm{S} 10 \mathrm{H})$. Thus, so far we were unable to find any functional consequences of Rab11FIP5-P652L substitution, suggesting that core Rab11FIP5 properties are not affected. Further studies will be needed to uncover the kinetic or binding defects of Rab11FIP5 variants, especially within the context of neuronal cells.

\section{Discussion}

Numerous studies have implicated genetics in the etiology of ASDs, and recent results have implicated hundreds of genes and chromosomal regions as candidate ASD predisposition loci. These include chromosomal rearrangements as well as sequence variants. None of these candidates accounts for more than a small portion of ASD cases, and it is clear, based on the apparent complexity of autism genetics, that many genes are still undiscovered. In multiplex ASD pedigrees, it has been suggested that inherited genetic variants are more likely to be responsible, while in simplex families de novo variants may be more important $[8,16]$.

We used a discovery/validation strategy based on identifying inherited genetic variants in two- to nine-generation ASD families, followed by a case/control analysis of those variants in DNA samples from unrelated children with autism and children with normal development, to identify putative familial ASD predisposition genes. Using haplotype analysis we identified shared genomic segments within the families, and used DNA sequencing and CNV analysis to identify potential causal mutations on those haplotypes. We also followed this with a large case/control study to determine if any of the variants we identified might play a role in the general population of individuals with ASD.

We showed previously that identification of CNVs in a family-based discovery cohort could identify copy number variants relevant to the general ASD population 
[27]. In this paper, we applied the same strategy to the family-based identification of DNA sequence variants, and also follow up on our CNV analysis by providing information regarding segregation of some of these CNVs in our high-risk ASD families.

We identified 39 SNPs that are likely to affect protein function that have segregation patterns and ASD case allele frequencies suggestive of a role in ASD predisposition. Thirty-one of these variants result in nonconservative amino acid substitutions, five are predicted to affect splicing (three of these are predicted to affect both splicing and protein coding), and three introduce premature termination codons. Two variants were identified in the $A K A P 9$ gene and the JMJD7 gene (or the JMJD7-PLA2G4B fusion gene), and two different variants were identified that affect the same amino acid residue in the RAB11FIP5 gene; so collectively, these SNPs identify 36 potential ASD risk genes.

With the exception of two-generation families, and consistent with our haplotype sharing results, no sequence variants or CNVs implicated as ASD predisposition loci segregate to all affected individuals in a pedigree. This is consistent with previous genetic studies, which to date have been unable to demonstrate segregation of a single ASD risk locus in an extended family (for example see [52]). In our pedigree 5 (Figure 6), two independent risk variants, a single nucleotide variant in $A K A P 9$ and a deletion $\mathrm{CNV}$ in or near NRXN1, segregate to different branches of the family. Other risk variants also are found in individuals with ASD in this family, including two sequence variants with odds ratios greater than 1.5 in our population study. These results suggest that even in extended families that might be predicted to be segregating a single risk allele with reduced penetrance, multiple risk alleles in different ASD predisposition loci may be necessary. The results further suggest that use of specific inheritance models when evaluating autism genetics in large families should be approached with caution. Further, given our sequencing results and CNVs, the data suggest that a two-pronged approach, involving both DNA sequencing and microarray-based $\mathrm{CNV}$ analysis, may be necessary for a complete genetic diagnosis of children with ASDs.
Eleven of the putative autism risk variants that we identified in our high-risk families are further supported by data from our case/control study. Three of these variants each were seen in a single ASD case (out of 1,541 total cases) and in none of 5,785 controls. Familial variants that we detected in eight additional genes are more common in ASD cases than in controls, and each has an odds ratio greater than 1.5. Although these variants are rare (all have frequencies of $<0.01$ in our case/control study), their identification in affected individuals in our ASD families and their increased prevalence in unrelated affected individuals support their role as potential ASD risk loci.

Several intriguing observations resulted from an extensive literature review of the functions and mechanistic actions of each of these 36 genes and their encoded proteins. A number of the genes have been previously linked to autism or other neurological disorders or have known neurological functions (Table 5) (11 out of 36 genes, or $31 \%)$. The functions of several other genes belong to pathways often cited as having relevance to autism. These include genes encoding proteins with immunological functions (inflammatory response), and genes encoding proteins important for energy metabolism and mitochondrial function. These groups account for 19 of the 36 genes on the list (53\%). Other genes have as yet unexplored functions, can only be linked to functions based on sequence similarity, or have scattered roles in many other cellular or organismal processes, such as cell cycle control, angiogenesis, protein degradation, or metalloproteinase activity.

The incidence/prevalence of autism has been reported to be as high as 1 in 38 children [68], while the estimated prevalence in the US is reported to be approximately 1 in 88 [69]. Multiple factors, including genetic, epigenetic and environmental, are thought to be necessary for autism development. As with previous work involving familial autism, we found that no single gene variant described here can account for every case of autism in our pedigrees. This may reasonably be expected of a multigenic disorder with high prevalence in the population. It also is consistent with the high likelihood that autism represents a number of different conditions, at least at the genetic level, all

Table 5 Biological functions/pathways of genes with variants found in children with ASDs

\begin{tabular}{|c|c|c|}
\hline Function & Gene names & References \\
\hline Previously associated with autism & TRPM1, RAB11FIP5, AKAP9, SCN3A & {$[27,43,49,53]$} \\
\hline $\begin{array}{l}\text { Previously associated with neurological } \\
\text { disorder (other than autism) }\end{array}$ & $\begin{array}{l}\text { RELN (autosomal recessive lissencephaly), ALX1 (facial clefting, micropthalmia), } \\
\text { CCDC85C (seizures), EPB41L1 (intellectual disability) }\end{array}$ & {$[44,45,50,54-56]$} \\
\hline Neural function & ITPK1, CLMN, PRTG & [57-59] \\
\hline Mitochondrial function & PLA2G4B, c7orf10, PDK4, C14orf2 & {$[60-63]$} \\
\hline Inflammatory response/Immune function & DEFB124, BPI, RNF31, IRF9 & {$[64-67]$} \\
\hline
\end{tabular}


under the same phenotypic umbrella called autism. Several variants that we identified, however, represent excellent candidates for significant risk factors for autism based on their known functions and the currently understood molecular pathways involved in autism. We discuss the most compelling cases below.

\section{RAB11FIP5}

RAB11FIP5 is a member of a family of scaffolding proteins for the RAS GTPase, Rab11. Specifically, RAB11FIP5 has been characterized as a key player in apical endosome recycling, plasma membrane recycling and transcytosis $[70,71]$. We identified a $\mathrm{P} 652 \mathrm{~L}$ variant in three affected siblings in a family of six members, in which the mother is an unaffected P652L carrier. An additional variant resulting in a $\mathrm{P} 652 \mathrm{H}$ substitution also was detected in 1/1,541 Caucasian ASD cases and 0/ 5,785 Caucasian children with normal development (Table 3). These variants modify a conserved proline within the C-terminus of RAB11FIP5.

Heterozygous disruption of RAB11FIP5 was observed previously in a ten year old boy with a balanced translocation $(46, \mathrm{XY}, \mathrm{t}(2 ; 9)(\mathrm{p} 13 ; \mathrm{p} 24))$ that disrupts only the RAB11FIP5 gene [43]. This individual has a clinical diagnosis of PDD-NOS, an autism spectrum disorder. This translocation led the authors to suggest that haploinsufficiency of RAB11FIP5 contributes to the subject's ASD. RAB11FIP5 works closely in conjunction with RAB11, and its presence has been detected in both presynaptic and post-synaptic densities where Rab11 plays a key role in determining synaptic strength in long-term depression [72], regulates norepinephrine transporter trafficking [73], carries out synaptic glutamate receptor recycling [74], and regulates dendritic branching in response to BDNF [75,76]. All of these functions have been suggested to be significant contributors to the etiology of ASDs [77,78] and further support the role of mutations in RAB11FIP5 as ASD risk alleles.

\section{AKAP9}

AKAP9 is a member of a family of over 50 proteins that serve as scaffolding partners for PKA, its effectors, and phosphorylation targets. AKAP9, also known as Yotiao, is chiefly expressed in the heart and brain, where the encoded protein serves as a scaffold for PKA, protein phosphatase I, NMDA receptors, the heart potassium channel subunit KCNQ1, IP3R1, and specific isoforms of adenylyl cyclase [79-83]. The subcellular localization and assembly of these multimeric protein scaffolds, mediated by AKAPs, are thought to be essential for function, since disruption of the interaction between the AKAP and its effectors leads to a loss of activity. In the case of KCNQ1, loss of interaction between AKAP9 and KCNQ1 leads to a potentially fatal heart condition, long-QT syndrome, which also arises in cases with loss of function mutations in KCNQ1 itself [84].

We identified two variants in the AKAP9 gene. These variants result in R3233C and R3832C substitutions in the encoded protein. These two variants were coincident with autism and were found in two unrelated extended ASD pedigrees (Figure 6, Additional file 7: Figure S6). The R3233C variant was additionally found in our case/control study. A recent meta-study of the genes identified from the five major autism GWAS studies and autism candidate genes arising from alternative methodologies, such as large scale CNV studies, placed AKAPS as a central, integral gene family linking many of the pathways identified by bioinformatics [49]. Given its role in localizing PKA, adenylyl cyclase isoforms and NMDAR in the postsynaptic scaffold, AKAP9 represents a protein that, like its better-characterized counterpart AKAP5, could function in synaptic transmission and plasticity, glutamatergic receptor function regulation and recycling, and dendritic spine morphology [85].

It is notable that two of the genes (MOK, TRPM1) containing potential ASD risk alleles were partially or completely encompassed by risk CNVs observed in our previous study [27]. This suggests that the same genes may be affected by different genetic mechanisms with the same or similar phenotypic result. The CNVs containing these genes were both copy number losses. The $M O K$ sequence variant described here was a nonsense change, while the TRPM1 variant was a missense change. These results are consistent with the $M O K$ and TRPM1 effects being due to haploinsufficiency at these two loci.

Our data demonstrate the complex nature of autism genetics. Although the heritability for autism is quite high, our data show that numerous genetic variants may confer risk to ASD even in a single family. This finding is consistent with the results of a whole genome sequencing study that used both a recessive model and model independent analyses to identify several potential ASD risk variants in an ASD family with two affected individuals [86]. Consistent with the large number of potential ASD risk genes identified to date, none of the genes identified in this single multiplex ASD family overlapped with the genes identified in our study. Our study adds to this complexity by identifying sequence variants in regions of haplotype sharing in 30 high-risk ASD families of two to six generations. Our data further demonstrate that in very large multi-generation families, the likelihood of additional risk variants entering the family from individuals who marry into the pedigree is high. These results are consistent with the prevalence of autism in the population and the high heritability for autism seen in numerous studies. Future studies will be necessary to characterize the biological roles that the variants we 
identified play in the complex set of disorders that comprise ASD.

\section{Conclusions}

Our study is the first to use an empirical approach to identify shared genomic segments, followed by sequence variant detection, to identify potential ASD risk variants in a large set of autism families. We identified 39 DNA sequence variants in 36 genes that may represent ASD risk genes. Eleven of these variants may also be risk variants in unrelated ASD cases, as they were shown to have odds ratios greater than 1.5 in a large ASD case/control population. Twenty-eight of these variants were observed only in high-risk ASD families in our study. These very rare sequence changes also may identify additional ASD risk genes. Segregation patterns demonstrate that in multi-generation ASD families, multiple genetic variants, including CNV and SNP risk variants, may contribute to ASD risk.

\section{Additional files}

Additional file 1: Table S1. Pedigree structure. Table S2. Literature ASD risk genes sequenced. Table S3. Primers for variant amplification and sequencing. Table S4 List of all confirmed variants. Table S5. Analysis of potential risk variants.

Additional file 2: Figure S1. Haplotype sharing in high-risk autism pedigrees. The figures show a graphic representation of haplotype sharing among affected individuals in a pedigree, created using the HapShare program. The X-axis represents chromosomal coordinates for the designated chromosomes. The Y-axis represents various combinations of haplotype sharing among affected individuals in the pedigree, listed arbitrarily by iteration number. The lowest value on the $\mathrm{Y}$-axis represent sharing among all $\mathrm{N}$ affected individuals in the pedigree, and where all $\mathrm{N}$ individuals share, there is only one possible combination. With lower degrees of sharing there are more possibilities. For example, in pedigree 10 with six affected individuals, there is only one possible way for all six to share the same haplotype. Where only five of six share the haplotype, there are six different ways to get this result, with each of the six affected individuals being excluded from sharing in each of the six iterations shown. Red indicates sharing among $\mathrm{N}$ out of $\mathrm{N}$ affected individuals in the pedigree, with other colors representing lower degrees of sharing. Panel a) two regions of chromosome 2 shared by all six affected individuals in pedigree 10; panel b) sharing among all six affected individuals in pedigree 10 of a chromosome 14 region; panel c) sharing among five of eight affected individuals on chromosome 7 in pedigree 5 and sharing among four of seven affected individuals on chromosome 20 in pedigree 4 . The variants found on these haplotypes are indicated by the gene names in the figure. Note that the chromosome 7 region identified in pedigree 5 as being shared among eight affected individuals was later shown not to be shared by an additional affected family member, resulting in a final count of sharing among five of nine affected individuals.

Additional file 3: Figure S2. Segregation of sequence variants in SCN3A and OIP5 and CNVs involving LINGO2 in pedigree 10. Pedigree 10 has 6 affected male siblings. The female sibling in the lowest generation has trisomy 21 and includes some features of autism. The LINGO2 loss CNV was shown to have an odds ratio of 3.74 in our case/control study, while the LINGO2 gain CNV did not have a clinically relevant odds ratio in the broad ASD population. The SCN3A sequence variant was not observed in our case/control study while the OIP5 variant yielded an odds ratio of 2.25. Pedigree symbols are described in the legend for Figure 2. Sequence variants identified in the family are shown in the black boxes. All family members with DNA available were tested for all variants.
Additional file 4: Figure S3. SNP genotype clusters. Genotype clusters for all SNPs observed in the case/control study (Table 3) are shown.

Additional file 5: Figure S4. Sanger sequence confirmation of variants in the RAB11FIP5, AUP1, SCN3A, ATP11B, KLHL6, C7orf10, AKAP9, HEPACAM2, PDK4, RELN, ABP1, ALX1, AP1G2, DCAF11, RNF31, IRF9, SDR39U1 and PRKD1 genes. Heterozygous positions are indicated by the blue line in the center of each panel.

Additional file 6: Figure S5. Sanger sequence confirmation of variants in the SEC23A, ITPK1, CLMN, CCDC85C, MOK, C140rf2, TRPM1, FMN1, PGBD4, OIP5, JMJD7, JMJD7-PLA2G4B, CASC4, SPATA5L1, PYGO1, PRTG, NUDT7, $D E F B 124$ and EPB41L1 genes. Heterozygous positions are indicated by the blue line in the center of each panel.

Additional file 7: Figure S6. Segregation of a second AKAP9 variant in a small pedigree. Pedigree 6 has a single affected child. Pedigree symbols are described in the legend for Figure 2. A link between this pedigree and other high-risk autism pedigrees is indicated by blue boxes. Sequence variants identified in the family are shown in the black boxes. Odds ratios for the variants observed in the case/control study are shown in parentheses. Variants with no odds ratio were observed only in high-risk families. All family members were tested for all variants unless no DNA was available. Individuals with no available DNA are indicated.

Additional file 8: Figure S7. Segregation of an $A L X 1$ variant in a small two-generation pedigree. Pedigree 6 has two siblings affected with autism. A single $A L X 1$ variant is shared by both siblings. A link between this pedigree and another high-risk autism pedigree is indicated by the blue box. Pedigree symbols are described in the legend for Figure 2 . Sequence variants identified in the family are shown in the black boxes. Odds ratios for the variants observed in the case/control study are shown in parentheses. Variants with no odds ratio were observed only in high-risk families. All family members were tested for all variants.

Additional file 9: Figure S8. Multigeneration pedigree with multiple sequence variants and overlapping loss and gain copy number variants. Pedigree 8 has 5 affected male children. Potential causal variants in this family do not segregate to more than one affected individual. CNVs identified in 4 individuals [27] are shown in red boxes. Pedigree symbols are described in the legend for Figure 2. Sequence variants identified in the family are shown in the black boxes. Odds ratios for the variants observed in the case/control study are shown in parentheses. Variants with no odds ratio were observed only in high-risk families. All family members were tested for all variants unless no DNA was available. Individuals with no available DNA are indicated.

Additional file 10: Figure S9. Segregation of two sequence variants in a two-generation pedigree. Pedigree 9 has three affected female siblings. Pedigree symbols are described in the legend for Figure 2. Sequence variants identified in the family are shown in the black boxes. All family members were tested for all variants.

Additional file 11: Figure S10. Effects of RAB11FIP5 P652L on RAB11 binding. (A) Wild- type of P652L mutant FIP5(490-653) was incubated with either various GST-tagged Rabs or GST-tagged FIPs. Beads were then washed and bound FIP5(490-653) eluted with $1 \%$ SDS. Eluates were then analyzed by immunoblotting with anti-Rab11FIP5 antibodies. (B-G) HeLa cells were transduced with either wild-type FIP5-GFP (A and D) or FIP5-GFP-P652L (E and G). Cells were then fixed and stained with anti-transferrin receptor antibodies (C, D, F and G). D and E are merged images, with yellow representing the extent of overlap between Rab11FIP5 and transferrin receptor. (H) HeLa cells expressing either FIP5-GFP or FIP5-GFP-P652L were incubated with $1 \mathrm{\mu g} / \mathrm{ml}$ of transferrin-Alexa488. Cells were then washed and incubated in serum-supplemented media varying amount of time. Cell-associated (not recycled) transferrin-Alexa488 was measured using flow cytometry. Data shown are the means of two independent experiments.

\section{Abbreviations}

ASD: Autism spectrum disorder; CNV: Copy number variant; SNP: Single nucleotide polymorphism; NCBI: National Center for Biotechnology Information; UPDB: Utah Population Database; ADI-R: Autism Diagnostic Interview-Revised; 
ADOS: Autism Diagnostic Observation Schedule; CHOP: The Children's Hospital of Philadelphia; PCA: Principal component analysis; MAF: Minor allele frequency; HWE: Hardy-Weinberg equilibrium; GST: Glutathione S-transferase; SDS: Sodium dodecyl sulfate; PDD-NOS: Pervasive developmental disorder not otherwise specified.

\section{Competing interests}

GBC and CGL are paid employees of Golden Helix Inc., which derives commercial revenue from the SNP \& Variation Suite software used for data analysis for this publication. NM, CHH and MFL have stock options and patent applications with Lineagen, Inc. MFL also is an unpaid scientific advisor for Lineagen, Inc. $\mathrm{CHH}$ is an employee of, and $\mathrm{KH}$ is a former employee of, Lineagen, Inc. The remaining authors declare no competing interests. Financial support from Lineagen, Inc. does not alter our adherence to all the Molecular Autism policies on sharing data and materials.

\section{Authors' contributions}

NM designed experiments, performed DNA sequencing and molecular analysis, analyzed data and contributed to writing of the manuscript. $\mathrm{CHH}$ designed experiments, oversaw data analysis, and wrote much of the manuscript. LB performed molecular confirmation assays on high-risk family sequence variants and designed and performed melting curve assays for SNP confirmation. JS and BO performed sequence analysis for identifying sequence variants in our high-risk autism families. TL performed haplotype sharing analysis on our high-risk ASD families. TV handled all aspects of autism family DNA sample QC and tracking. DH contributed to experimental design. JTG supervised all data release and performed QC on all data generated at CHOP. RP supervised sequencing work at CHOP and oversaw data quality. CK and KT generated and helped analyze most of the arraybased SNP data generated at CHOP. FW oversaw all aspects of DNA sample handling of CHOP samples. FGO performed Sanger sequencing and analysis to confirm variants in $\mathrm{CHOP}$ samples. $\mathrm{KH}$ evaluated the biological roles of all genes with variants and contributed to writing of the manuscript. GBC performed data QC and analysis, and contributed to writing of the manuscript. DL and RP performed and evaluated RAB11FIP5 functional assays and wrote portions of the manuscript. CGL, HH and MFL, oversaw lab and analytical operations, aided significantly in experimental design and setup, contributed to the writing of the manuscript and approved the final version of the manuscript. All authors read and approved the final manuscript.

\section{Acknowledgements}

All family subjects were ascertained and DNA collected with support from R01 MH 06359 from the National Institute of Mental Health and U19HD035476 from the National Institute of Child Health and Human Development. Utah DNA samples were processed with support from GCRC M01-RR025764 from the National Center for Research Resources. The authors gratefully acknowledge the resources provided by the Autism Genetic Resource Exchange (AGRE) Consortium and the participating AGRE families.

\section{Author details}

${ }^{1}$ Department of Human Genetics, University of Utah, Salt Lake City, UT, USA ${ }^{2}$ Lineagen, Inc, Salt Lake City, UT, USA. ${ }^{3}$ Center for Applied Genomics, The Children's Hospital of Philadelphia, Philadelphia, PA, USA. ${ }^{4}$ Golden Helix, Inc, Bozeman, MT, USA. ${ }^{5}$ Department of Cell and Developmental Biology, School of Medicine, University of Colorado Anschutz Medical Campus, Aurora, CO, USA. ${ }^{6}$ Department of Pediatrics, University of Pennsylvania School of Medicine, Philadelphia, PA, USA.

\section{Received: 11 September 2013 Accepted: 24 December 2013}

Published: 27 January 2014

\section{References}

1. Rosenberg RE, Law JK, Yenokyan G, McGready J, Kaufmann WE, Law PA: Characteristics and concordance of autism spectrum disorders among 277 twin pairs. Arch Pediatr Adolesc Med 2009, 163:907-914.

2. Hallmayer J, Cleveland S, Torres A, Phillips J, Cohen B, Torigoe T, Miller J, Fedele A, Collins J, Smith K, Lotspeich L, Croen LA, Ozonoff S, Lajonchere C, Grether JK, Risch N: Genetic heritability and shared environmental factors among twin pairs with autism. Arch Gen Psychiatry 2011, 68:1095-1102.
3. Lichtenstein P, Carlström E, Råstam M, Gillberg C, Anckarsäter H: The genetics of autism spectrum disorders and related neuropsychiatric disorders in childhood. Am J Psychiatry 2010, 167:1357-1363.

4. Ronald A, Hoekstra RA: Autism spectrum disorders and autistic traits: a decade of new twin studies. Am J Med Genet B Neuropsychiatr Genet 2011, 156B:255-274.

5. International Molecular Genetic Study of Autism Consortium (IMGSAC): A full genome screen for autism with evidence for linkage to a region on chromosome 7q. Hum Mol Genet 1998, 7:571-578.

6. International Molecular Genetic Study of Autism Consortium (IMGSAC): A genomewide screen for autism: strong evidence for linkage to chromosomes 2q, 7q, and 16p. Am J Hum Genet 2001, 69:570-581.

7. Buxbaum JD, Silverman J, Keddache M, Smith CJ, Hollander E, Ramoz N, Reichert JG: Linkage analysis for autism in a subset families with obsessive-compulsive behaviors: evidence for an autism susceptibility gene on chromosome 1 and further support for susceptibility genes on chromosome 6 and 19. Mol Psychiatry 2004, 9:144-150.

8. Iosifov I, Ronemus M, Levy D, Wang Z, Hakker I, Rosenbaum J, Yamrom B, Lee Y-h, Narzisi G, Leotta A, Kendall J, Grabowska E, Ma B, Marks S, Rodgers L, Stepansky A, Troge J, Andrews P, Bekritsky M, Pradhan K, Ghiban E, Kramer M, Parla J, Demeter R, Fulton LL, Fulton RS, Magrini VJ, Ye K, Darnell J, Darnell RB, et al.: De novo gene disruptions in children on the autistic spectrum. Neuron 2012, 74(2):285-299.

9. Sanders SJ, Murtha MT, Gupta AR, Murdoch JD, Raubeson MJ, Willsey AJ, Ercan-Sencicek AG, DiLullo NM, Parikshak NN, Stein JL, Walker MF, Ober GT, Teran NA, Song Y, El-Fishawy P, Murtha RC, Choi M, Overton JD, Bjornson RD, Carriero NJ, Meyer KA, Bilguvar K, Mane SM, Sestan N, Lifton RP, Günel M, Roeder K, Geschwind DH, Devlin B, State MW: Disruptive de novo point mutations, revealed by whole-exome sequencing, are strongly associated with autism spectrum disorders. Nature 2012, 485(7397):237-241.

10. Neale BM, Kou Y, Liu L, Ma'ayan A, Samocha KE, Sabo A, Lin CF, Stevens C, Wang LS, Makarov V, Polak P, Yoon S, Maguire J, Crawford EL, Campbell NG, Geller ET, Valladares O, Schafer C, Liu H, Zhao T, Cai G, Lihm J, Dannenfelser R, Jabado O, Peralta Z, Nagaswamy U, Muzny D, Reid JG, Newsham I, Wu Y, et al: Patterns and rates of exonic de novo mutations in autism spectrum disorders. Nature 2012, 485(7397):242-245.

11. O'Roak BJ, Deriziotis P, Lee C, Vives L, Schwartz JJ, Girirajan S, Karakoc E, Mackenzie AP, Ng SB, Baker C, Rieder MJ, Nickerson DA, Bernier R, Fisher SE, Shendure J, Eichler EE: Exome sequencing in sporadic autism reveals a highly interconnected protein network and extreme locus heterogeneity. Nature 2012, 485(7397):246-250.

12. O'Roak BJ, Vives L, Fu W, Egertson JD, Stanaway IB, Phelps IG, Carvill G, Kumar A, Lee C, Ankenman K, Munson J, Hiatt JB, Turner EH, Levy R, O'Day DR, Krumm N, Coe BP, Martin BK, Borenstein E, Nickerson DA, Mefford HC, Doherty D, Akey JM, Bernier R, Eichler EE, Shendure J: Multiplex targeted sequencing identifies recurrently mutated genes in autism spectrum disorders. Science 2012, 338(6114):1619-1622.

13. Lim ET, Raychaudhuri S, Sanders SJ, Stevens C, Sabo A, MacArthur DG, Neale BM, Kirby A, Ruderfer DM, Fromer M, Lek M, Liu L, Flannick J, Ripke S, Nagaswamy U, Muzny D, Reid JG, Hawes A, Newsham I, Wu Y, Lewis L, Dinh $H$, Gross S, Wang LS, Lin CF, Valladares O, Gabriel SB, De Pristo M, Altshuler DM, Purcell SM, et al: Rare complete knockouts in humans: population distribution and significant role in autism spectrum disorders. Neuron 2013, 77(2):235-242.

14. Yu TW, Chahrour MH, Coulter ME, Jiralerspong S, Okamura-Ikeda K, Ataman B, Schmitz-Abe K, Harmin DA, Adli M, Malik AN, D'Gama AM, Lim ET, Sanders SJ, Mochida GH, Partlow JN, Sunu CM, Felie JM, Rodriguez J, Nasir RH, Ware J, Joseph RM, Hill RS, Kwan BY, Al-Saffar M, Mukaddes NM, Hashmi A, Balkhy S, Gascon GG, Hisama FM, LeClair E, et al: Using whole-exome sequencing to identify inherited causes of autism. Neuron 2013, 77(2):259-273.

15. Girirajan S, Brkanac Z, Coe BP, Baker C, Vives L, Vu TH, Shafer N, Bernier R, Ferrero GB, Silengo M, Warren ST, Moreno CS, Fichera M, Romano C, Raskind WH, Eichler EE: Relative burden of large CNVs on a range of neurodevelopmental phenotypes. PLoS Genet 2011, 7:e1002334.

16. Sebat J, Lakshmi B, Malhotra D, Troge J, Lese-Martin C, Walsh T, Yamrom B, Yoon S, Krasnitz A, Kendall J, Leotta A, Pai D, Zhang R, Lee YH, Hicks J, Spence SJ, Lee AT, Puura K, Lehtimäki T, Ledbetter D, Gregersen PK, Bregman J, Sutcliffe JS, Jobanputra V, Chung W, Warburton D, King MC, Skuse D, Geschwind DH, Gilliam TC, et al: Strong association of de novo copy number mutations with autism. Science 2007, 316:445-449. 
17. Marshall CR, Noor A, Vincent JB, Lionel AC, Feuk L, Skaug J, Shago M, Moessner R, Pinto D, Ren $Y$, Thiruvahindrapduram B, Fiebig A, Schreiber S, Friedman J, Ketelaars CE, Vos YJ, Ficicioglu C, Kirkpatrick S, Nicolson R, Sloman L, Summers A, Gibbons CA, Teebi A, Chitayat D, Weksberg R, Thompson A, Vardy C, Crosbie V, Luscombe S, Baatjes R, et al: Structural variation of chromosomes in autism spectrum disorder. Am J Hum Genet 2008, 82:477-488.

18. Christian SL, Brune CW, Sudi J, Kumar RA, Liu S, Karamohamed S, Badner JA, Matsui S, Conroy J, McQuaid D, Gergel J, Hatchwell E, Gilliam TC, Gershon ES, Nowak NJ, Dobyns WB, Cook EH Jr: Novel submicroscopic chromosomal abnormalities detected in autism spectrum disorder. Biol Psychiatry 2008, 63:1111-1117.

19. Glessner JT, Wang K, Cai G, Korvatska O, Kim CE, Wood S, Zhang H, Estes A, Brune CW, Bradfield JP, Imielinski M, Frackelton EC, Reichert J, Crawford EL, Munson J, Sleiman PM, Chiavacci R, Annaiah K, Thomas K, Hou C, Glaberson W, Flory J, Otieno F, Garris M, Soorya L, Klei L, Piven J, Meyer KJ, Anagnostou E, Sakurai T, et al: Autism genome-wide copy number variation reveals ubiquitin and neuronal genes. Nature 2009, 459:569-573.

20. Bucan M, Abrahams BS, Wang K, Glessner JT, Herman El, Sonnenblick LI, Alvarez Retuerto Al, Imielinski M, Hadley D, Bradfield JP, Kim C, Gidaya NB, Lindquist I, Hutman T, Sigman M, Kustanovich V, Lajonchere CM, Singleton A, Kim J, Wassink TH, McMahon WM, Owley T, Sweeney JA, Coon H, Nurnberger J, Li M, Cantor RM, Minshew NJ, Sutcliffe JS, Cook EH, et al: Genome-wide analyses of exonic copy number variants in a family-based study point to novel autism susceptibility genes. PLoS Genet 2009, 5:e1000536.

21. Pinto D, Pagnamenta AT, Klei L, Anney R, Merico D, Regan R, Conroy J, Magalhaes TR, Correia C, Abrahams BS, Almeida J, Bacchelli E, Bader GD, Bailey AJ, Baird G, Battaglia A, Berney T, Bolshakova N, Bölte S, Bolton PF, Bourgeron T, Brennan S, Brian J, Bryson SE, Carson AR, Casallo G, Casey J, Chung BH, Cochrane $\mathrm{L}$, Corsello $\mathrm{C}$, et al: Functional impact of global rare copy number variation in autism spectrum disorders. Nature 2010, 466:368-372.

22. Szatmari P, Paterson AD, Zwaigenbaum L, Roberts W, Brian J: Mapping autism risk loci using genetic linkage and chromosomal rearrangements. Nat Genet 2007, 39:319-328.

23. Sanders SJ, Ercan-Sencicek AG, Hus V, Luo R, Murtha MT, Moreno-De-Luca D, Chu SH, Moreau MP, Gupta AR, Thomson SA, Mason CE, Bilguvar K, Celestino-Soper PB, Choi M, Crawford EL, Davis L, Wright NR, Dhodapkar RM, DiCola M, DiLullo NM, Fernandez TV, Fielding-Singh V, Fishman DO, Frahm S, Garagaloyan R, Goh GS, Kammela S, Klei L, Lowe JK, Lund SC, et al: Multiple recurrent de novo CNVs, including duplications of the $7 q 11.23$ Williams syndrome region, are strongly associated with autism. Neuron 2011, 70:863-885.

24. Weiss LA, Shen Y, Korn JM, Arking DE, Miller DT, Fossdal R, Saemundsen E, Stefansson H, Ferreira MA, Green T, Platt OS, Ruderfer DM, Walsh CA, Altshuler D, Chakravarti A, Tanzi RE, Stefansson K, Santangelo SL, Gusella JF, Sklar P, Wu BL, Daly MJ: Autism consortium: association between microdeletion and microduplication at 16p11.2 and autism. N Engl J Med 2008, 358:667-675.

25. Morrow EM, Yoo SY, Flavell SW, Kim TK, Lin Y, Hill RS, Mukaddes NM, Balkhy S, Gascon G, Hashmi A, Al-Saad S, Ware J, Joseph RM, Greenblatt R, Gleason D, Ertelt JA, Apse KA, Bodell A, Partlow JN, Barry B, Yao H, Markianos K, Ferland RJ, Greenberg ME, Walsh CA: Identifying autism loci and genes by tracing recent shared ancestry. Science 2008, 321:218-223.

26. Jacquemont ML, Sanlaville D, Redon R, Raoul O, Cormier-Daire V, Lyonnet S, Amiel J, Le Merrer M, Heron D, de Blois MC, Prieur M, Vekemans M, Carter NP, Munnich A, Colleaux L, Philippe A: Array-based comparative genomic hybridization identifies high frequency of cryptic chromosomal rearrangements in patients with syndromic autism spectrum disorders. J Med Genet 2006, 43:843-849.

27. Matsunami N, Hadley D, Hensel CH, Christensen GB, Kim C, Frackelton E, Thomas K, da Silva RP, Stevens J, Baird L, Otterud B, Ho K, Varvil T, Leppert T, Lambert CG, Leppert M, Hakonarson H: Identification of rare recurrent copy number variants in high-risk autism families and their prevalence in a large ASD population. PLoS One 2013, 8(1):e52239.

28. Allen-Brady K, Robison R, Cannon D, Varvil T, Villalobos M, Pingree C, Leppert MF, Miller J, McMahon WM, Coon H: Genome-wide linkage in Utah autism pedigrees. Mol Psychiatry 2010, 15(10):1006-1015.

29. Coon H, Matsunami N, Stevens J, Miller J, Pingree C, Camp NJ, Thomas A, Krasny L, Lainhart J, Leppert MF, McMahon W: Evidence for linkage on chromosome 3q25-27 in a large autism extended pedigree. Hum Hered 2005, 60(4):220-226.
30. Allen-Brady K, Miller J, Matsunami N, Stevens J, Block H, Farley M, Krasny L, Pingree C, Lainhart J, Leppert M, McMahon WM, Coon H: A high-density SNP genome-wide linkage scan in a large autism extended pedigree. Mol Psychiatry 2009, 14(6):590-600.

31. BRLMM: An improved genotype calling method for the GeneChip ${ }^{\oplus}$ human mapping 500K array Set. http://media.affymetrix.com/support/ technical/whitepapers/brlmm_whitepaper.pdf.

32. O'Connell JR, Weeks DE: PedCheck: a program for identification of genotype incompatibilities in linkage analysis. Am J Hum Genet 1998, 63(1):259-266.

33. Arrington CB, Bleyl SB, Matsunami N, Bowles NE, Leppert TI, Demarest BL, Osborne K, Yoder BA, Byrne JL, Schiffman JD, Null DM, DiGeronimo R, Rollins M, Faix R, Comstock J, Camp NJ, Leppert MF, Yost HJ, Brunelli L: A family-based paradigm to identify candidate chromosomal regions for isolated congenital diaphragmatic hernia. Am J Med Genet A 2012, 158A(12):3137-3147

34. Langmead B, Trapnell C, Pop M, Salzberg SL: Ultrafast and memoryefficient alignment of short DNA sequences to the human genome. Genome Biol 2009, 10(3):R25.

35. Li H, Ruan J, Durbin R: Mapping short DNA sequencing reads and calling variants using mapping quality scores. Genome Res 2008, 18(11):1851-1858.

36. Hillier LW, Marth GT, Quinlan AR, Dooling D, Fewell G, Barnett D, Fox P, Glasscock JI, Hickenbotham M, Huang W, Magrini VJ, Richt RJ, Sander SN, Stewart DA, Stromberg M, Tsung EF, Wylie T, Schedl T, Wilson RK, Mardis ER: Whole-genome sequencing and variant discovery in C. elegans. Nat Methods 2008, 5(2):183-188.

37. Yandell M, Huff C, Hu H, Singleton M, Moore B, Xing J, Jorde LB, Reese MG: A probabilistic disease-gene finder for personal genomes. Genome Res 2011, 21(9):1529-1542.

38. Wang K, Li M, Hakonarson H: ANNOVAR: functional annotation of genetic variants from high-throughput sequencing data. Nucleic Acids Res 2010, 38(16):e164.

39. Kent WJ, Sugnet CW, Furey TS, Roskin KM, Pringle TH, Zahler AM, Haussler D: The human genome browser at UCSC. Genome Res 2002, 12(6):996-1006.

40. Meyer LR, Zweig AS, Hinrichs AS, Karolchik D, Kuhn RM, Wong M, Sloan CA, Rosenbloom KR, Roe G, Rhead B, Raney BJ, Pohl A, Malladi VS, Li CH, Lee BT, Learned K, Kirkup V, Hsu F, Heitner S, Harte RA, Haeussler M, Guruvadoo L, Goldman M, Giardine BM, Fujita PA, Dreszer TR, Diekhans M, Cline MS, Clawson $H$, Barber GP, et al: The UCSC Genome Browser database: extensions and updates 2013. Nucleic Acids Res 2013, 41(Database issue):D64-D69.

41. Junutula JR, Schonteich E, Wilson GM, Peden AA, Scheller RH, Prekeris R: Molecular characterization of Rab11 interactions with members of the family of Rab11-interacting proteins. J Bio/ Chem 2004, 279(32):33430-33437.

42. Peden AA, Schonteich E, Chun J, Junutula JR, Scheller RH, Prekeris R: The RCP-Rab11 complex regulates endocytic protein sorting. Mol Biol Cell 2004, 15(8):3530-3541.

43. Roohi J, Tegay DH, Pomeroy JC, Burkett S, Stone G, Stanyon R, Hatchwell E: A de novo apparently balanced translocation [46, XY, t(2;9)(p13;p24)] interrupting RAB11FIP5 identifies a potential candidate gene for autism spectrum disorder. Am J Med Genet B Neuropsychiatr Genet 2008, 147B(4):411-417.

44. Hong SE, Shugart YY, Huang DT, Shahwan SA, Grant PE, Hourihane JO, Martin ND, Walsh CA: Autosomal recessive lissencephaly with cerebellar hypoplasia is associated with human RELN mutations. Nat Genet 2000, 26(1):93-96

45. Zaki M, Shehab M, El-Aleem AA, Abdel-Salam G, Koeller HB, Ilkin Y, Ross ME, Dobyns WB, Gleeson JG: Identification of a novel recessive RELN mutation using a homozygous balanced reciprocal translocation. Am J Med Genet A 2007, 143A(9):939-944.

46. Béna F, Bruno DL, Eriksson M, van Ravenswaaij-Arts C, Stark Z, Dijkhuizen T, Gerkes E, Gimelli S, Ganesamoorthy D, Thuresson AC, Labalme A, Till M, Bilan F, Pasquier L, Kitzis A, Dubourgm C, Rossi M, Bottani A, Gagnebin M, Sanlaville D, Gilbert-Dussardier B, Guipponi M, van Haeringen A, Kriek M, Ruivenkamp C, Antonarakis SE, Anderlid BM, Slater HR, Schoumans J: Molecular and clinical characterization of 25 individuals with exonic deletions of NRXN1 and comprehensive review of the literature. Am J Med Genet B Neuropsychiatr Genet 2013, 162B(4):388-403.

47. Nag A, Bochukova EG, Kremeyer B, Campbell DD, Muller H, Valencia-Duarte AV, Cardona J, Rivas IC, Mesa SC, Cuartas M, Garcia J, Bedoya G, Cornejo W, Herrera LD, Romero R, Fournier E, Reus VI, Lowe TL, Farooqi IS, Mathews CA, McGrath LM, Yu D, Cook E, Wang K, Scharf JM, Pauls DL, Freimer NB, Plagnol V, 
Ruiz-Linares A: Tourette syndrome association international consortium for genetics: CNV analysis in Tourette syndrome implicates large genomic rearrangements in COL8A1 and NRXN1. PLOS One 2013, 8(3):e59061.

48. Schaaf CP, Boone PM, Sampath S, Williams C, Bader PI, Mueller JM, Shchelochkov OA, Brown CW, Crawford HP, Phalen JA, Tartaglia NR, Evans P, Campbell WM, Tsai AC, Parsley L, Grayson SW, Scheuerle A, Luzzi CD, Thomas SK, Eng PA, Kang SH, Patel A, Stankiewicz P, Cheung SW: Phenotypic spectrum and genotype-phenotype correlations of NRXN1 exon deletions. Eur J Hum Genet 2012, 20(12):1240-1247.

49. Poelmans G, Franke B, Pauls DL, Glennon JC, Buitelaar JK: AKAPs integrate genetic findings for autism spectrum disorders. Transl Psychiatry 2013, 3:e270.

50. Liao HM, Fang JS, Chen YJ, Wu KL, Lee KF, Chen CH: Clinical and molecular characterization of a transmitted reciprocal translocation $\mathrm{t}(1 ; 12)(\mathrm{p} 32.1$; q21.3) in a family co-segregating with mental retardation, language delay, and microcephaly. BMC Med Genet 2011, 12:70.

51. Schonteich E, Wilson GM, Burden J, Hopkins CR, Anderson K, Goldenring JR, Prekeris R: The Rip11/Rab11-FIP5 and kinesin II complex regulates endocytic protein recycling. J Cell Sci 2008, 121(Pt 22):3824-3833.

52. Kilpinen H, Ylisaukko-oja T, Rehnström K, Gaál E, Turunen JA, Kempas E, von Wendt L, Varilo T, Peltonen L: Linkage and linkage disequilibrium scan for autism loci in an extended pedigree from Finland. Hum Mol Genet 2009, 18(15):2912-2921.

53. Chen CP, Lin SP, Chern SR, Chen YJ, Tsai FJ, Wu PC, Wang W: Array-CGH detection of a de novo $2.8 \mathrm{Mb}$ deletion in $2 \mathrm{q} 24.2 \rightarrow \mathrm{q} 24.3$ in a girl with autistic features and developmental delay. Eur J Med Genet 2010, 53(4):217-220.

54. Uz E, Alanay Y, Aktas D, Vargel I, Gucer S, Tuncbilek G, von Eggeling F, Yilmaz E, Deren O, Posorski N, Ozdag H, Liehr T, Balci S, Alikasifoglu M, Wollnik B, Akarsu NA: Disruption of $A L X 1$ causes extreme microphthalmia and severe facial clefting: expanding the spectrum of autosomal-recessive $A L X$-related frontonasal dysplasia. Am J Hum Genet 2010, 86(5):789-796.

55. Mori N, Kuwamura M, Tanaka N, Hirano R, Nabe M, Ibuki M, Yamate J: Ccdc85c encoding a protein at apical junctions of radial glia is disrupted in hemorrhagic hydrocephalus (hhy) mice. Am J Pathol 2012, 180(1):314-327.

56. Hamdan FF, Gauthier J, Araki Y, Lin DT, Yoshizawa Y, Higashi K, Park AR, Spiegelman D, Dobrzeniecka S, Piton A, Tomitori H, Daoud H, Massicotte C, Henrion E, Diallo O, S2D Group, Shekarabi M, Marineau C, Shevell M, Maranda B, Mitchell G, Nadeau A, D'Anjou G, Vanasse M, Srour M, Lafrenière RG, Drapeau P, Lacaille JC, Kim E et al: Excess of de novo deleterious mutations in genes associated with glutamatergic systems in nonsyndromic intellectual disability. Am J Hum Genet 2011, 88(3):306-316.

57. Majerus PW, Wilson DB, Zhang C, Nicholas PJ, Wilson MP: Expression of inositol 1,3,4-trisphosphate 5/6-kinase (ITPK1) and its role in neural tube defects. Adv Enzyme Regul 2010, 50(1):365-372.

58. Marzinke MA, Clagett-Dame M: The all-trans retinoic acid (atRA)-regulated gene Calmin (Clmn) regulates cell cycle exit and neurite outgrowth in murine neuroblastoma (Neuro2a) cells. Exp Cell Res 2012, 318(1):85-93.

59. Wong YH, Lu AC, Wang YC, Cheng HC, Chang C, Chen PH, Yu JY, Fann MJ: Protogenin defines a transition stage during embryonic neurogenesis and prevents precocious neuronal differentiation. J Neurosci 2010, 30(12):4428-4439.

60. Ghosh M, Loper R, Gelb MH, Leslie CC: Identification of the expressed form of human cytosolic phospholipase A2beta (cPLA2beta): cPLA2beta3 is a novel variant localized to mitochondria and early endosomes. $J$ Biol Chem 2006, 281(24):16615-16624

61. Sherman EA, Strauss KA, Tortorelli S, Bennett MJ, Knerr I, Morton DH, Puffenberger EG: Genetic mapping of glutaric aciduria, type 3, to chromosome 7 and identification of mutations in c7orf10. Am J Hum Genet 2008, 83(5):604-609.

62. Korotchkina LG, Patel MS: Site specificity of four pyruvate dehydrogenase kinase isoenzymes toward the three phosphorylation sites of human pyruvate dehydrogenase. J Biol Chem 2001, 276(40):37223-37229.

63. Meyer B, Wittig I, Trifilieff E, Karas M, Schägger H: Identification of two proteins associated with mammalian ATP synthase. Mol Cell Proteomics 2007, 6(10):1690-1699.

64. Jarczak J, Kościuczuk EM, Lisowski P, Strzałkowska N, Jóźwik A, Horbańczuk J, Krzyżewski J, Zwierzchowski L, Bagnicka E: Defensins: natural component of human innate immunity. Hum Immunol 2013, 74(9):1069-1079.

65. Holweg A, Schnare M, Gessner A: The bactericidal/permeability-increasing protein (BPI) in the innate defense of the lower airways. Biochem Soc Trans 2011, 39(4):1045-1050.
66. Tokunaga F, Iwai K: Linear ubiquitination: a novel NF-KB regulatory mechanism for inflammatory and immune responses by the LUBAC ubiquitin ligase complex. Endocr J 2012, 59(8):641-652.

67. Nguyen $\mathrm{H}$, Hiscott J, Pitha PM: The growing family of interferon regulatory factors. Cytokine Growth Factor Rev 1997, 8(4):293-312.

68. Kim YS, Leventhal BL, Koh YJ, Fombonne E, Laska E, Lim EC, Cheon KA, Kim SJ, Kim YK, Lee H, Song DH, Grinker RR: Prevalence of autism spectrum disorders in a total population sample. Am J Psychiatry 2011, 168(9):904-912.

69. Center for Disease Control and Prevention. http://www.cdc.gov/ncbddd/ autism/data.html.

70. Prekeris R, Klumperman J, Scheller RH: A Rab11/Rip11 protein complex regulates apical membrane trafficking via recycling endosomes. $\mathrm{Mol} \mathrm{Cell}$ 2000, 6(6):1437-1448.

71. Hales CM, Griner R, Hobdy-Henderson KC, Dorn MC, Hardy D, Kumar R, Navarre J, Chan EK, Lapierre LA, Goldenring JR: Identification and characterization of a family of Rab11-interacting proteins. J Biol Chem 2001, 276(42):39067-39075.

72. Fernández-Monreal M, Brown TC, Royo M, Esteban JA: The balance between receptor recycling and trafficking toward lysosomes determines synaptic strength during long-term depression. J Neurosci 2012, 32(38):13200-13205.

73. Matthies HJ, Moore JL, Saunders C, Matthies DS, Lapierre LA, Goldenring JR, Blakely RD, Galli A: Rab11 supports amphetamine-stimulated norepinephrine transporter trafficking. J Neurosci 2010, 30(23):7863-7877.

74. van der Sluijs P, Hoogenraad CC: New insights in endosomal dynamics and AMPA receptor trafficking. Semin Cell Dev Biol 2011, 22(5):499-505.

75. Park M, Salgado JM, Ostroff L, Helton TD, Robinson CG, Harris KM, Ehlers MD: Plasticity-induced growth of dendritic spines by exocytic trafficking from recycling endosomes. Neuron 2006, 52(5):817-830.

76. Lazo OM, Gonzalez A, Ascaño M, Kuruvilla R, Couve A, Bronfman FC: BDNF regulates Rab11-mediated recycling endosome dynamics to induce dendritic branching. J Neurosci 2013, 33(14):6112-6122.

77. Penzes P, Cahill ME, Jones KA, VanLeeuwen JE, Woolfrey KM: Dendritic spine pathology in neuropsychiatric disorders. Nat Neurosci 2011, 14(3):285-293.

78. Ebert DH, Greenberg ME: Activity-dependent neuronal signaling and autism spectrum disorder. Nature 2013, 493(7432):327-337.

79. Piggot J, Shirinyan D, Shemmassian S, Vazirian S, Alarcón M: Neural systems approaches to the neurogenetics of autism spectrum disorders. Neuroscience 2009, 164(1):247-256.

80. Lin L, Sun W, Kung F, Dell'Acqua ML, Hoffman DA: AKAP79/150 impacts intrinsic excitability of hippocampal neurons through phosphoregulation of A-type K + channel trafficking. J Neurosci 2011, 31(4):1323-1332.

81. Westphal RS, Tavalin SJ, Lin JW, Alto NM, Fraser ID, Langeberg LK, Sheng M, Scott JD: Regulation of NMDA receptors by an associated phosphatasekinase signaling complex. Science 1999, 285(5424):93-96.

82. Marx SO, Kurokawa J, Reiken S, Motoike H, D'Armiento J, Marks AR, Kass RS: Requirement of a macromolecular signaling complex for beta adrenergic receptor modulation of the KCNQ1-KCNE1 potassium channel. Science 2002, 295(5554):496-499.

83. Tu H, Tang TS, Wang Z, Bezprozvanny I: Association of type 1 inositol 1,4,5-trisphosphate receptor with AKAP9 (Yotiao) and protein kinase A. J Biol Chem 2004, 279(18):19375-19382.

84. Chen L, Marquardt ML, Tester DJ, Sampson KJ, Ackerman MJ, Kass RS: Mutation of an A-kinase-anchoring protein causes long-QT syndrome. Proc Natl Acad Sci USA 2007, 104(52):20990-20995.

85. Keith DJ, Sanderson JL, Gibson ES, Woolfrey KM, Robertson HR, Olszewski K, Kang R, El-Husseini A, Dell'acqua ML: Palmitoylation of A-kinase anchoring protein 79/150 regulates dendritic endosomal targeting and synaptic plasticity mechanisms. J Neurosci 2012, 32(21):7119-7136.

86. Shi L, Zhang X, Golhar R, Otieno FG, He M, Hou C, Kim C, Keating B, Lyon GJ, Wang $K$, Hakonarson $H$ : Whole-genome sequencing in an autism multiplex family. Mol Autism 2013, 4(1):8.

doi:10.1186/2040-2392-5-5

Cite this article as: Matsunami et al:: Identification of rare DNA sequence variants in high-risk autism families and their prevalence in a large case/control population. Molecular Autism 2014 5:5. 